\title{
Hydrogeological effects of dredging navigable canals through lagoon shallows. A case study in Venice
}

Pietro Teatini $^{1,2,3}$, Giovanni Isotton ${ }^{2}$, Stefano Nardean ${ }^{1}$, Massimiliano Ferronato ${ }^{1,2}$, Annamaria Mazzia ${ }^{1}$, Cristina Da Lio ${ }^{3}$, Luca Zaggia ${ }^{3}$, Debora Bellafiore ${ }^{3}$, Massimo Zecchin ${ }^{4}$, Luca Baradello ${ }^{4}$, Francisco Cellone ${ }^{5}$, Fabiana Corami $^{6}$, Andrea Gambaro ${ }^{6,7}$, Giovanni Libralato ${ }^{7,8}$, Elisa Morabito ${ }^{6}$, Annamaria Volpi Ghirardini ${ }^{7}$, Riccardo Broglia ${ }^{9}$, Stefano Zaghi ${ }^{9}$, and Luigi Tosi ${ }^{3}$

${ }^{1}$ Department of Civil, Environmental and Architectural Engineering, University of Padua, via Trieste 63, 35121 Padua (PD), Italy

${ }^{2}$ M3E S.r.l., via Giambellino 7, 35129 Padua (PD), Italy

${ }^{3}$ Institute of Marine Sciences, National Research Council, Arsenale Tesa 104, Castello 2737/F, Venice 30122, Italy

${ }^{4}$ National Institute of Oceanography and Experimental Geophysics (OGS), Borgo Grotta Gigante 42/c, 34010 Sgonico (TS), Italy

${ }^{5}$ Centro de Investigaciones Geologicas, Consejo Nacional de Investigaciones Científicas y Tecnicas, Diagonal 113 No. 275, B1904DPK, La Plata, Argentina

${ }^{6}$ Institute of the Dynamics for the Environmental Processes, CNR-IDPA, Campus Scientifico, Ca' Foscari University of Venice, Via Torino, 155, 30172, Mestre-Venice, Italy

${ }^{7}$ Department of Environmental Sciences, Informatics and Statistics, Ca' Foscari University of Venice, Via Torino, 155, 30172, Mestre-Venice, Italy

${ }^{8}$ Department of Biology, University of Naples Federico II, Complesso Universitario di Monte S. Angelo, Via Cinthia ed. 7, 80126 Naples, Italy

${ }^{9}$ CNR-INSEAN, National Research Council-Marine Technology Research Institute, Via di Vallerano 139, 00128 Rome, Italy

Correspondence to: Pietro Teatini (pietro.teatini@unipd.it)

Received: 31 May 2017 - Discussion started: 6 June 2017

Revised: 11 September 2017 - Accepted: 27 September 2017 - Published: 15 November 2017

\begin{abstract}
For the first time a comprehensive investigation has been carried out to quantify the possible effects of dredging a navigable canal on the hydrogeological system underlying a coastal lagoon. The study is focused on the Venice Lagoon, Italy, where the port authority is planning to open a new $10 \mathrm{~m}$ deep and $3 \mathrm{~km}$ long canal to connect the city passenger terminal to the central lagoon inlet, thus avoiding the passage of large cruise ships through the historic center of Venice. A modeling study has been developed to evaluate the short (minutes), medium (months), and long (decades) term processes of water and pollutant exchange between the shallow aquifer system and the lagoon, possibly enhanced by the canal excavation, and ship wakes. An in-depth characterization of the lagoon subsurface along the channel has supported the numerical modeling. Piezometer and sea level records, geophysical acquisitions, laboratory analyses of groundwa-
\end{abstract}

ter and sediment samples (chemical analyses and ecotoxicity testing), and the outcome of 3-D hydrodynamic and computational fluid dynamic (CFD) models have been used to set up and calibrate the subsurface multi-model approach. The numerical outcomes allow us to quantify the groundwater volume and estimate the mass of anthropogenic contaminants ( $\mathrm{As}, \mathrm{Cd}, \mathrm{Cu}, \mathrm{Cr}, \mathrm{Hg}, \mathrm{Pb}, \mathrm{Se}$ ) likely leaked from the nearby industrial area over the past decades, and released into the lagoon from the canal bed by the action of depression waves generated by ships. Moreover, the model outcomes help to understand the effect of the hydrogeological layering on the propagation of the tidal fluctuation and salt concentration into the shallow brackish aquifers underlying the lagoon bottom. 


\section{Introduction}

Coastal lagoons are transient ecosystems highly sensitive to changes in sedimentation, sea level rise, and land subsidence. In many cases, their evolution over the last centuries has been strongly impacted by human activities. The use of these peculiar ecosystems, for fish and shell farming, tourism, and transportation of people and goods, has usually contrasted with the preservation and protection of habitat and biodiversity (Kennish and Paerl, 2010). One typical intervention in coastal systems is dredging of canals and inlets, which may be performed to increase the water volume exchanged with the sea (Gong et al., 2008) or for navigation purposes (Fortunato and Oliveiram, 2007; Healy et al., 1996). Elsewhere, dredging has been used as a source of fill material for adjacent upland development and land reclamation (López et al., 2013).

The opening of waterways in shallow coastal waterbodies and lagoons has facilitated navigation for centuries, providing sheltered routes and permitting safe access to inland ports and harbours. However, the progressively increasing tonnage of vessels and sediment dynamics requires port authorities worldwide to implement dredging programmes to guarantee navigability and to open new shipping channels to allow larger traffic.

In many cases, this practice has led to environmental deterioration, by changing the flushing efficiency of the canal system, aggravating salinity stratification, re-suspending fine sediments, pollutants, and nutrients, which are responsible for eutrophication, hypoxic events, and increasing contamination and release of pollutants (e.g., Newell et al., 1998). For example, the combined impacts of increased turbidity and physical removal or burial during dredging caused a loss of approximately $81 \%$ of the seagrass in Tampa Bay, Florida (Erftemeijer and Lewis, 2006). Moreover, canal dredging has been responsible for significant hydro-morphological impacts in coastal lagoons. A significant example is the case of Aveiro Lagoon in Portugal, where 2 centuries of channelization, jetty breakwater construction, and dredging have led to a progressive shift from the original fluvially dominated system into the present tidally dominated one. The associated stresses imposed by increased tidal currents have led to important changes in the sedimentary regime (Duck and da Silva, 2012).

In the Venice Lagoon, Italy, engineers and administrations have planned dredging works for centuries, creating a series of canals for navigation and reclaimed land for urban expansion and industrial settlement (Balletti, 2006; D'Alpaos, 2010). The last major navigable canal, the MalamoccoMarghera Industrial Canal (MMIC), was excavated in 1970 to connect the Porto Marghera Industrial Zone (PMIZ) on the mainland with the Adriatic Sea through the Malamocco inlet (Fig. 1a). A large number of studies developed over the last decade has demonstrated that the MMIC and the navigation of large vessels through the lagoon shallows have

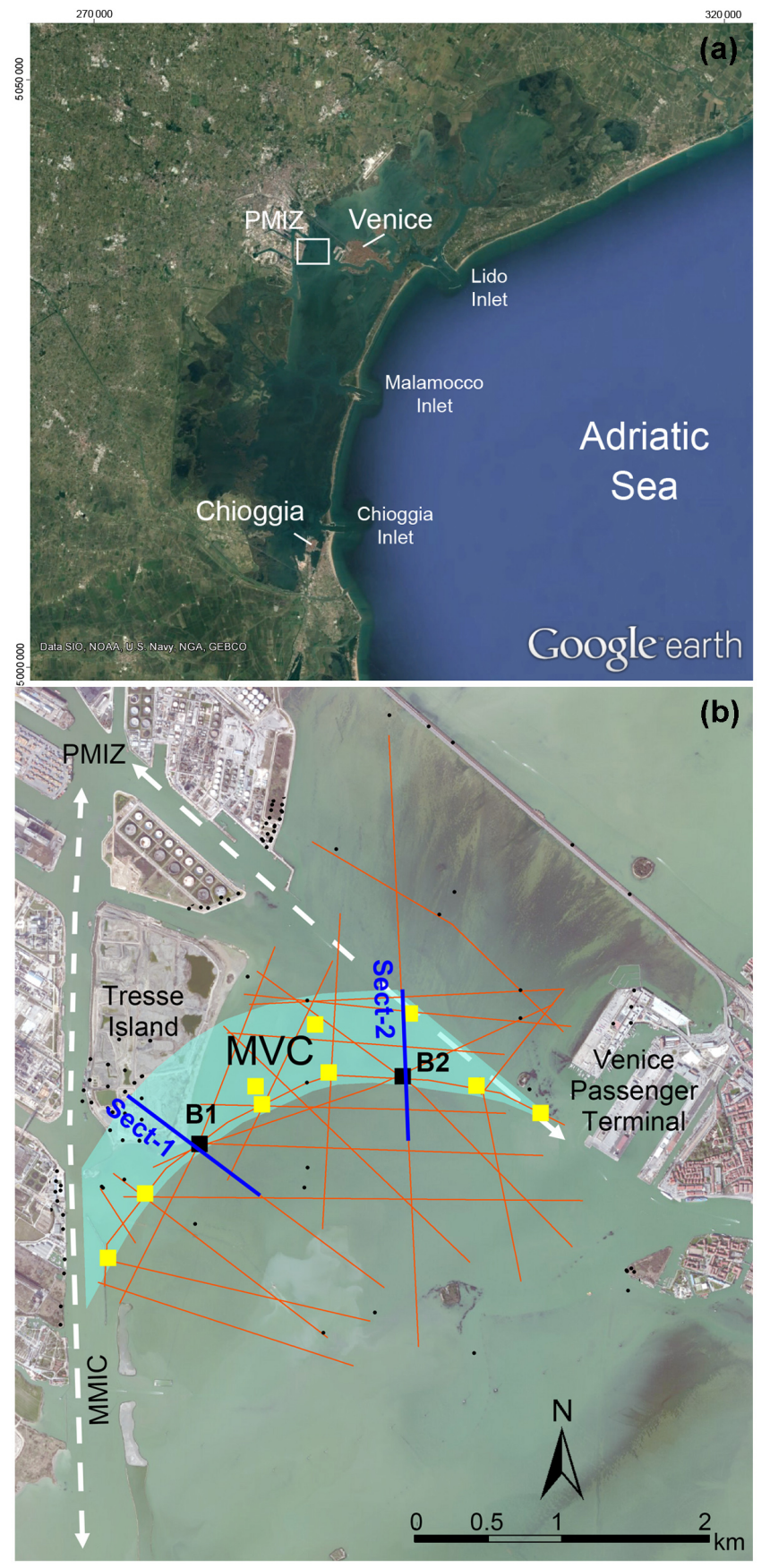

Figure 1. (a) Satellite view of the Venice Lagoon and (b) map of the study area. The zone involved in the MVC dredging is highlighted in light blue, with the main navigation canals shown by the dashed alignments. The traces of Section-1 and Section- 2 are shown in blue and those of the seismic survey in red. The square dots represent the location of the new $10 \mathrm{~m}$ deep boreholes; the small black dots indicate the positions of previous hydro-stratigraphic investigations used to drive the interpretation of the seismic sections. 
likely been the main causes of the morphological deterioration observed in the central lagoon as deepening of the tidal flats, marshland erosion, and sediment loss (e.g., Amos et al., 2010; Carniello et al., 2009; Ferrarin et al., 2013; Marani et al., 2011; Molinaroli et al., 2009; Tambroni and Seminara, 2006). The Venice Port Authority recently planned the excavation of a new approximately $3 \mathrm{~km}$ long and $10 \mathrm{~m}$ deep navigation canal (called the Marghera-Venice Canal, MVC in the following) to reroute vessels along the MMIC and reach the passenger terminal located in the southwestern part of the historic center (Fig. 1b). The intervention should avoid the transit of large cruise liners though the historic center of Venice. At present, more than 500 cruise ships enter the lagoon each year (http://www.vtp.it/en/company/statistics/), and this traffic will add to the already intense commercial traffic that is based on the MMIC.

Despite the large research effort dedicated to the understanding of the freshwater-groundwater exchange in coastal aquifers (e.g., Li et al., 1999; Michael et al., 2005; Nakada et al., 2011; Qu et al., 2014), studies developed in the past have never addressed the evaluation of possible effects of excavating navigable canals through tidal flats on the underlying hydrogeological system. However, in-depth investigations using direct measurements (isotopes, benthic chambers), geophysical surveys, and modeling simulations revealed that submarine groundwater discharge (SGD) may provide considerable freshwater inputs to coastal waterbodies (e.g., Rapaglia et al., 2010; Wang et al., 2015) and may be the primary pathway for nutrients and other contaminants to enter coastal lagoons (e.g., Rapaglia, 2005; Rocha et al., 2016; Santos et al., 2008; Tait et al., 2013).

The primary objectives of this study are to investigate how the construction of a new large navigable canal through tidal flats affects (i) the groundwater flow and quality of the shallow aquifers underlying the lagoon bottom and (ii) the exchange of water and chemicals from the subsurface to the surface waterbodies. Our research focuses on the Venice Lagoon as a representative case study. Based on the available knowledge on the surface and subsurface lagoon environment, the following issues had to be considered in the context of the study.

- The quality of the surficial water, mainly its salinity, with respect to the groundwater. Can an eventual cut of impervious layers enhance saltwater leakage beneath the lagoon bottom?

- The presence of chemicals in the groundwater below the lagoon bottom and the sediment toxicity due to leakage from the industrial and urban centers located in the lagoon surroundings. Are contaminants present also along the MVC designed path? Which is their mobility? And can the MVC excavation determine their release into the lagoon, also favored by SGD from exposed sub-surficial heterogeneities?
- The evolution of water level in the lagoon canals and flats due to the transit of large vessels. How do the solitary waves associated with the passage of large vessels in the navigation channel influence the flow and contaminant transfer between the subsurface and surficial systems?

In this study, for the first time, we explore in detail these issues, improving the understanding of the interaction between the subsurface and surface waters in coastal systems, and providing quantitative evaluations for the specific case study. This is carried out through an accurate investigation of the lagoon environment along the MVC trace and the use of uncoupled and coupled density-dependent groundwater flow and transport simulators.

The paper is organized as follows. Section 2 presents the dataset available to characterize the subsurface system of the Venice Lagoon along the MVC and the factors forcing its dynamics. The numerical approach used to perform the hydrogeological modeling study is revised in Sect. 3 together with the description of the model setup. The results obtained by the computations are presented in Sect. 4, pointing out the effect of the canal dredging by comparing the model solutions in the present (i.e., without the canal) and planned (i.e., with the canal) scenarios. A discussion (Sect. 5) and a concluding section (Sect. 6) close the paper, evaluating the main outcomes in a general context and summarizing the principal results of the study.

\section{The central Lagoon of Venice: available dataset}

\subsection{Hydro-stratigraphic characterization}

About $40 \mathrm{~km}$ of very-high-resolution seismic (VHRS) lines (Fig. 1b) were collected by a boomer system equipped with an electro-dynamic plate and a single-channel streamer. The latter consisted of eight equidistant piezoelectric elements housed in an oil-filled tube and connected in series with a $2.8 \mathrm{~m}$ active array section (Tosi et al., 2009). The frequency bandwidth produced by the plate ranged from 0.4 to $9 \mathrm{kHz}$, thus allowing a decimeter resolution. Suitable floaters kept the streamer as shallow as possible to avoid destructive interference between reflected signals and multiple events from the air-water interface. Because the investigated area is characterized by shallow water $(<1.5 \mathrm{~m})$ and the conventional acquisition geometry (streamer towed behind a source) generates poor results using a single-channel streamer, a transverse geometry was applied to collect more coherent events (Baradello and Carcione, 2008). The seismic data were processed by a conventional sequence, including initially spherical divergence removal, secondly a time-variant gain, and finally a time-variant band-pass filter. The marine and boat waves degraded the reflection signal in a number of profiles. This effect was mitigated by computing a mean trace in a 
given interval, cross-correlating it with the single traces, and applying the corresponding time shift as a static correction.

The interpretation of the seismic units with the support of stratigraphic data obtained through 10 continuous $10 \mathrm{~m}$ long cores (Fig. 1b) specifically drilled for the study allowed us to sketch the hydro-stratigraphic setting of the lagoon subsoil along the MVC designed trace. In addition, a variety of geophysical, lithological, sedimentological, and geotechnical information available from previous investigations (Fabbri et al., 2013; Madricardo and Donnici, 2014; Teatini et al., 2011; Tosi et al., 2007, 2011; Zecchin et al., 2011, 2014) was reprocessed to characterize the architecture of the deeper deposits (down to a depth of approximately $50 \mathrm{mb}$ b.m.s.l.) and contextualize the investigated area within a regional hydrogeological framework. Figure 2 shows two interpreted VHRS lines, namely Section-1 and Section-2, orthogonal to the MVC trace. The seismic survey revealed a high heterogeneity of the lagoon subsoil due to a number of buried paleochannels, whose presence would not have been highlighted only by the core samples. This study is focused on these two sections, each of them crossing a $10 \mathrm{~m}$ depth borehole. The borehole coordinates are the following: $286467^{\circ}$ east, $5034726^{\circ}$ north (Section-1), and $287843^{\circ}$ east, $5035184^{\circ}$ north (Section-2), UTM33 WGS84.

Combining the new hydro-stratigraphic information and that available from previous studies, it has been possible to characterize the hydro-stratigraphic system and identify three main permeable units down to about $50 \mathrm{~m}$ depth beneath the lagoon bottom (Fig. 2). In the easternmost Section-1, the shallowest sandy unit (Aqf-1) is 7 to $10 \mathrm{~m}$ thick and lies below a silty-muddy layer a few meters thick (Aqt-1). Aqf- 1 is almost continuous in the central and southern parts of the investigated area and decreases northward where silty-clay deposits prevail. This aquifer represents a buried paleo-channel, whose direction is from the industrial zone to the historical center of Venice. The top of Aqf-1 represents the HolocenePleistocene limit. This is marked by an erosional unconformity generally made by a metric cemented clayey layer (Tosi et al., 2007), known in the Venice area as "caranto". A second sandy unit (Aqf-2) is generally confined below a $2-3 \mathrm{~m}$ thick silty-clayey layer (Aqt-2). In the central-western part of the study area where Section-2 is located, Aqt-2 is lacking because of paleo-channel incisions, and Aqf- 1 and Aqf-2 are undifferentiated. At the bottom of Aqf-2, a second quite continuous aquitard (Aqt-3) confines a third aquifer (Aqf-3), which has a regional extent. The Aqf-3 depth ranges between -25 and $-35 \mathrm{~m}$ b.m.s.l. and the thickness amounts to about $8 \mathrm{~m}$.

\subsection{Hydrogeological characterization}

Despite the large effort carried out in the past to define the hydrogeological setting of the shallow lagoon subsurface, scarce information is available in the study area because the characterization was mainly concentrated along the littoral strips. A $100 \mathrm{~km}$ long airborne electromagnetics (AEM) survey carried out in 2009 between Venice and the industrial area pointed out the important hydrogeologic function played by the caranto (Teatini et al., 2011). The AEM investigation provided resistivity information from the lagoon bottom down to about 120-140 $\mathrm{m}$ depth and clearly showed that the caranto reduces or precludes the downward leakage of seawaters. Groundwater with a salt concentration comparable with the marine waters (resistivity $\rho$ ranging between 0.1 and $1 \Omega \mathrm{m}$ ) is encountered below this impermeable layer only where it is missing because of natural erosion or canal dig. The measured $\rho$ values increased to $2-10 \Omega \mathrm{m}$ in the shallowest portion of the Pleistocene deposits, with almost freshwater groundwater $(\rho>10 \Omega \mathrm{m})$ below $10-30 \mathrm{~m}$ depth depending on the position. This strategic role may have considerable implications for the MVC project.

Groundwater and hydrogeologic properties in the upper $10 \mathrm{~m}$ in depth have been investigated by a Casagrande piezometer installed at the bottom of the boreholes along Section-1 and Section-2. Each monitoring station was instrumented by two CTD-Divers, one placed within the borehole and connected to the Casagrande cell and the other fixed outside the borehole casing at the lagoon bottom. The configuration allowed the simultaneous monitoring of electrical conductivity (EC), temperature $(T)$, and pressure $(P)$ in Aqf-1 and lagoon waters, thus revealing the possible relationship between the surface and subsurface waterbodies.

Figure 3 shows an example of the recorded Aqf- 1 pressure head and lagoon level during a few days in March 2016 at the Section-2 station. As expected, the fluctuation of the groundwater level is phased on the semi-diurnal tidal regime, with a gentle (10-15\%) reduction of the wave height and a delay of 10-20 min on the maximum/minimum occurrence. Similar values were obtained at the Section-1 borehole. Concerning EC, the records are characterized by a negligible variability in time. With reference to a temperature $T=25^{\circ} \mathrm{C}, \mathrm{EC}=46-51$ and $47-53 \mathrm{mS} \mathrm{cm}^{-1}$ in the lagoon water at Section-1 and Section-2, respectively. In Aqf-1, EC is approximately $15-20 \%$ higher in Section- 1 and smaller in Section-2, respectively, than the surface water. The differences suggest a possible groundwater contamination of anthropogenic origin in Section-1, which is close to PMIZ and the Tresse islands made of muds dredged from the PMIZ canals, and the effect exerted by the caranto in reducing the aquifer salinization in Section-2.

\subsection{Chemical characterization}

Among the various pollutants, trace elements are of particular concern since they are taken up by biota and may have toxic effects. Some trace elements are on the priority list and regulated by European directives, e.g., the 2000/60 EC (Water Framework Directive), and their national transpositions, e.g., Ministerial Decree 260/2010 in Italy. Furthermore, laws and decrees regulate the presence of trace elements in spe- 

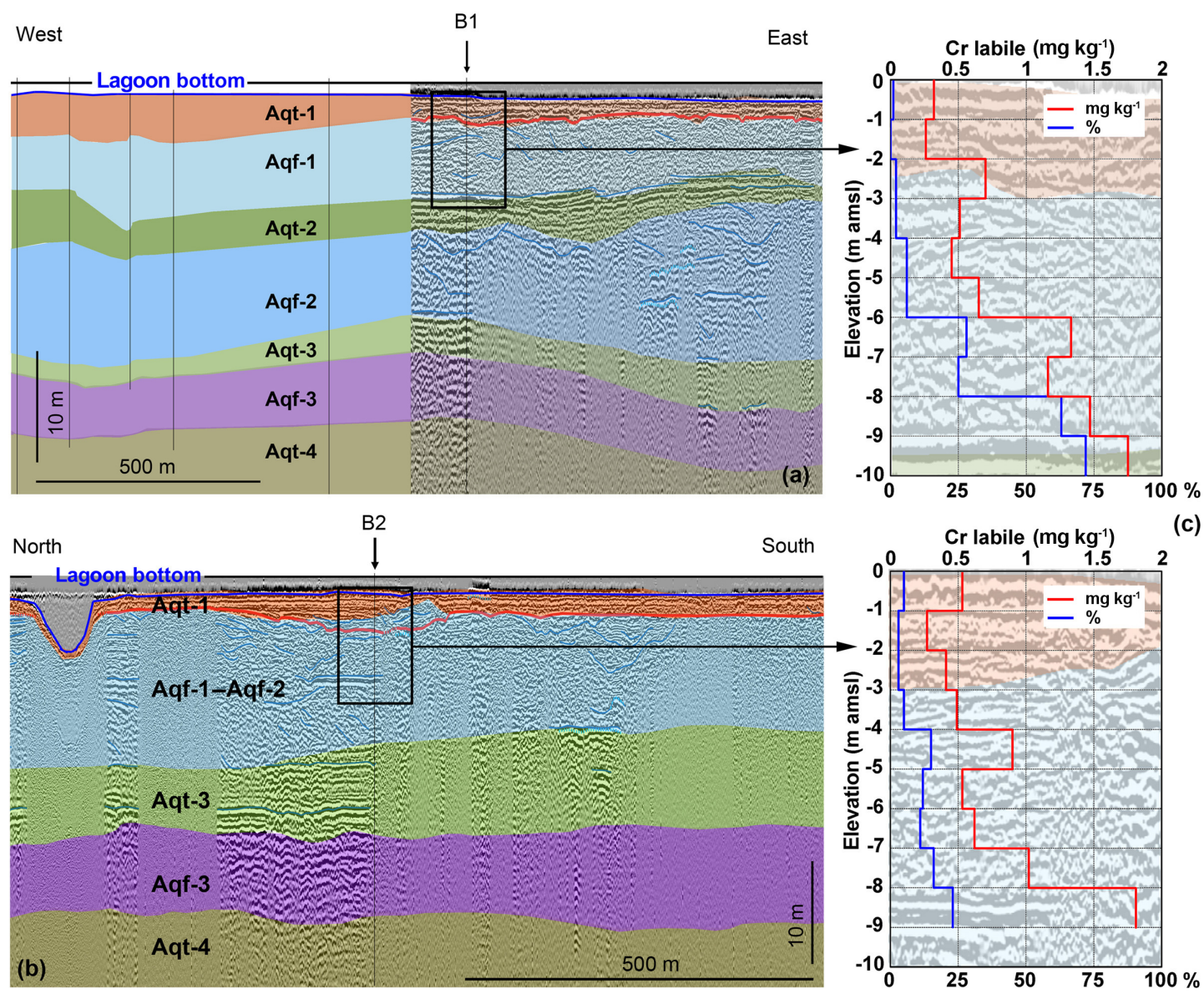

Figure 2. Hydrogeological setting of the subsurface of the Venice Lagoon along (a) Section-1 and (b) Section-2 (see Fig. 1 for their location) as obtained by the interpretation of the seismic acquisitions integrated with wellbore lithostratigraphies. The borehole locations are shown by $\mathrm{B} 1$ and B2. (c) Labile fraction in $\mathrm{mg} \mathrm{kg}^{-1}$ wet weight, and percentage of labile fraction with respect to the total concentration of Cr versus depth in the B1 and B2 boreholes.

cific relation to dredging. Before any dredging, the chemical characterization together with an eco-toxicological evaluation must be carried out. Although in the past much interest has been focussed on the total concentration of trace elements, it has more recently been accepted that assessing the mobility, the bioavailability, the bioaccessibility, and the toxicity of metals is fundamental (Schintu et al., 2016; Zhang et al., 2017).

Within this study, both the total concentration of trace elements and the geo-speciation, defined according to Ure et al. (1993), were carried out on samples collected from the two reference boreholes along Section-1 and Section2 (Fig. 1b). The geo-speciation was performed via the sequential extraction procedure (SEP) proposed by Tessier et al. (1979) and harmonized by Corami et al. (2009). The SEP allows an operational classification of metals into four geochemical fractions with different mobility, bioavailability, and bioaccessibility: labile, bound to oxyhydroxides of iron and manganese, bound to organic matters and sulfides, residual. Mobility decreases from the first fraction, i.e., labile, to

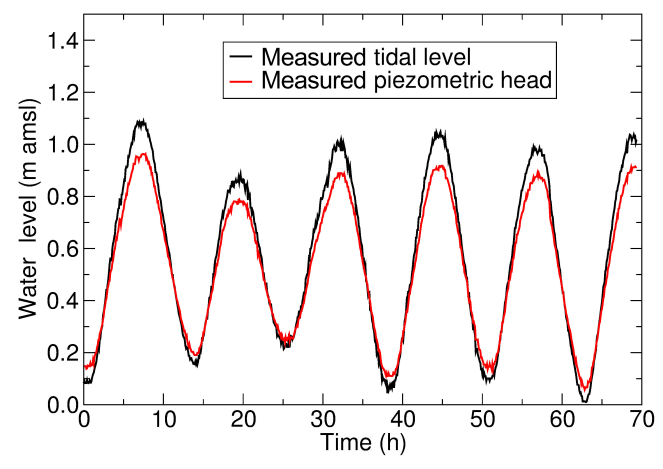

Figure 3. Measured tidal level and piezometric head at the Section2 borehole over the period between 7 and 10 March 2016

the residual, which is inert. The labile fraction is bioaccessible and bioavailable, with the second and third fractions that may become accessible to biota according to their mobility, e.g., in the case of anoxic events, or during dredging opera- 
tion. The labile fraction is composed of a readily exchangeable portion and a portion bound to carbonates, which are readily available for the uptake by the benthic fauna, i.e., the biota living in and on the sediments and, due to the sediment resuspension, for the uptake by the biota in the water column (Qiao et al., 2013; Lee et al., 2017).

A detailed description of the preparative and analytical methods employed to assess the total concentration and to study the geo-speciation is besides the aim of this paper and the reader can refer to DAIS (2016). Briefly, a hydraulic corer was used to collect the samples. Dried aliquots of sediments, previously homogenized for each meter interval, were assessed for the total concentration of the 12 trace elements (As, $\mathrm{Be}, \mathrm{Cd}, \mathrm{Cr}, \mathrm{Cu}, \mathrm{Hg}, \mathrm{Ni}, \mathrm{Pb}, \mathrm{Sb}, \mathrm{Se}, \mathrm{V}, \mathrm{Zn}$ ), in compliance with EU Directive 2013/39 and the Memorandum of Understanding dated 8 April 1993 between the Italian Ministry of the Environment, Veneto Region, Province of Venice, Venice and Chioggia Municipality, on the "Criteria for the safety of the environment during excavation, movement, and reemployment of muds dredged from the Venice channels", also known as "Protocollo 93". Unaltered aliquots were analyzed by the harmonized SEP to quantify the labile and bioaccessible fraction of some trace elements, namely $\mathrm{As}, \mathrm{Cd}, \mathrm{Cu}, \mathrm{Cr}$, $\mathrm{Hg}, \mathrm{Pb}$, and $\mathrm{Se}$. Figure $2 \mathrm{c}$ provides an example of the results obtained by the chemical characterization in terms of labile $\mathrm{Cr}$ concentration versus depth measured in the B1 (Section1) and B2 (Section-2) boreholes. As a general feature, the labile and bioaccessible fraction increases with depth. This trend has been confirmed at Section-1 for every trace element considered by this study and, to a lesser extent $(\mathrm{Cd}$ and $\mathrm{Pb})$, in Section-2.

\subsection{Ecotoxicological characterization}

Ecotoxicity is of great interest in sediment assessment and management, providing an integrated response related to the bioavailable and bioaccessible fraction of contaminants within the checked matrix (whole sediment, pore water, and elutriates). The sediment samples collected in Section-1 and Section-2 were homogenized and sieved at $2 \mathrm{~mm}$ (in a $\mathrm{N}_{2}$ atmosphere for pore water (PW) production). Ecotoxicity was investigated on sediments and aqueous extracts such as elutriates (E) and PWs prepared according to Arizzi Novelli et al. (2006) and Losso et al. (2009), respectively. A battery of toxicity tests was used, including acute (A) and (sub-)chronic ((S)C) endpoints with Vibrio fischeri (A) (ISO 21338:2010, whole sediment) and Corophium orientale (A) (ISO 16712:2005, whole sediment), Phaeodactylum tricornutum (C) (ISO 10253:2006, growth inhibition test on E and PW), Crassostrea gigas (SC) (ISO 17244:2015, embryotoxicity test on E and PW), Mytilus galloprovincialis (SC) (ISO 17244:2015, embryotoxicity test on E), and Paracentrotus lividus (A) (Volpi Ghirardini et al., 2005, sperm-cell toxicity on PW and embryotoxicity on E). Possible confounding factors, like $\mathrm{NH}_{3}$ and $\mathrm{S}_{2}$, were assessed as well (Libralato et al., 2008). Toxicity data were managed according to their relative standard protocol and integrated into a final judgement considering the worst-case scenario approach according to the precautionary principle.

The results showed a toxicity range from absent/low (acute tests) to very high (i.e., all embryotoxicity tests) considering as ranking tools the toxicity scales set up on a speciesby-species basis for Venice Lagoon sediments (Losso et al., 2010). According to the worst-case scenario approach, sediment presented very high levels of toxicity independently of the core depth (from 0 to $-8 \mathrm{~m}$ below the lagoon bottom), showing potential high risk for early life stages of sensitive marine organisms like bivalves and sea urchins. The increase in labile and bioaccessible fractions of metals along depth gradients could explain this evidence of toxicity being the response to the real bioaccessibility of contaminants in aqueous media.

\subsection{Hydrodynamic characterization}

Apart from the natural tidal regime, a certain effect on the hydrogeological system in the surroundings of deep channels is expected to be driven by long inverse solitary waves associated with the passage of large vessels in the navigation channel and known as depression wakes, or Bernoulli wakes (Rapaglia et al., 2015). Ship wakes were characterized by means of water level measurements made with pressure sensors and turbidity meters deployed along a profile on the channel side and the surrounding mudflat together with a modeling chain capable of reproducing the hydrodynamic patterns in the channel around the hull of the moving ship, and the propagation of the depression wake on the tidal flat.

Tidal level and ship-induced depression wakes as well as short-period boat wakes were measured with a pressure sensor with a logger (Solo D/Wave, RBR, Canada) immersed at a depth of approximately $4 \mathrm{~m}$ on the eastern side of the MMIC. Pressure was recorded by the instrument at a sampling frequency of $16 \mathrm{~Hz}$ and converted into depth data. The experimental setup also included an electromagnetic current meter deployed at the bottom of the navigation channel which recorded water level, current speed, and direction at an acquisition frequency of $2 \mathrm{~Hz}$. Simultaneously, an automatic identification system (AIS) receiver permitted us to acquire traffic data for the area, relating every observed event to the specific ship in transit in the measurement section. Tidal levels were referred to the local datum, while depression wakes were calculated as the difference between maximum and minimum levels at the passage of a ship. Figure 4 shows the ship wake generated by the passage of a large commercial vessel on 6 April 2016. A relatively small rise in the water level $(\sim 0.1 \mathrm{~m})$ before the ship reaches the measurement section is followed soon after the transit by a significant depression $(\sim 1.6 \mathrm{~m})$ that develops within the channel and propagates in the mudflat. The depression wake lasted for about $80 \mathrm{~s}$. 


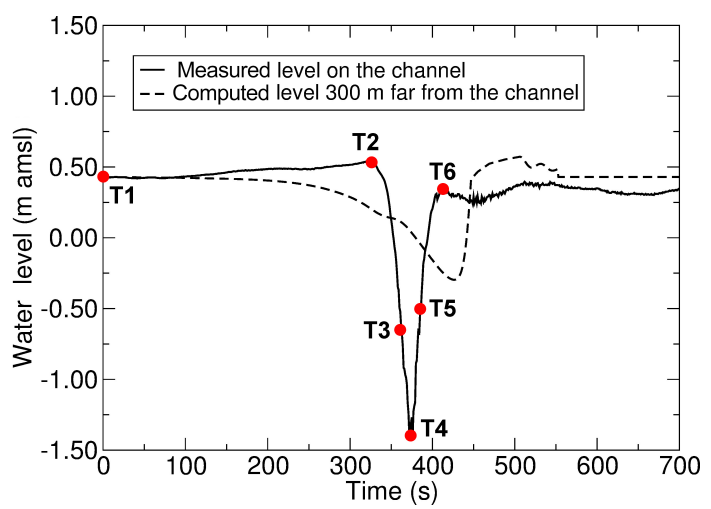

Figure 4. Water level (ma.m.s.l.) recorded on the bottom of the MMIC and computed by SHYFEM on the tidal flat $300 \mathrm{~m}$ from the channel caused by the transit on 6 April 2016 of the Cargo-Hazard A. The commercial vessel, which was used as a reference, is $280 \mathrm{~m}$ long, $40 \mathrm{~m}$ wide, and characterized by a gross tonnage of $66433 \mathrm{t}$. The ship speed $s$ was equal to 8.1 knots $\left(4.2 \mathrm{~m} \mathrm{~s}^{-1}\right)$. The time steps T1-T6 highlighted by red dots refer to the model outcome shown in Fig. 10.

The simulation of the pressure and velocity fields around the hull of the ship was carried out using the uRaNSeXnavis simulator (Broglia et al., 2014; Di Mascio et al., 2007, 2009). It is a finite volume solver based on the discretization of free surface, incompressible, viscous, highReynolds-number fluid equations (unsteady Reynolds averaged Navier-Stokes equations). The fluid-dynamical field is discretized using the overlapping grid approach, with an increase in spatial resolution close to the hull and the free surface, and then degrading in the channel close to the tidal flat. The channel and the lateral zone where the bathymetry is deeper than $2 \mathrm{~m}$ represent the uRaNSe-Xnavis domain. An example of the computational grid is shown in Fig. 5a. The model was tested and calibrated using the data recorded along the MMIC and then applied to forecast the movement of a typical cruise along the planned MVC.

The high-resolution CFD steady-state dimensionless results, in terms of water level and velocity, were interpolated on a regular $0.7 \times 0.7 \times 0.4 \mathrm{~m}$ grid, dimensionalized, and used to force a shallow water hydrodynamic code called SHYFEM (Shallow Water Hydrodynamic Finite Element Model) (Bellafiore and Umgiesser, 2010; Umgiesser et al., 2004). The finite element grid representing the portion of the Venice Lagoon with the MVC trace is shown in Fig. 5b. At each time step the uRaNSe-Xnavis results are geolocalized within the SHYFEM finite element grid and moved along the ship trajectory at a defined speed $s$. Water levels and 3-D velocities force the system. SHYFEM solves the shallow water equations in the whole computational basin shown in Fig. 5b, except the area covered by the uRaNSe-Xnavis results, which is the box including the ship and a portion of the surrounding channel (Fig. 5a), where a combined technique imposing and nudging input data is adopted. The evolution of the wa-
Table 1. Geometry of the typical cruise vessel used in the uRaNSeXnavis and SHYFEM simulations.

\begin{tabular}{lr}
\hline Length $(\mathrm{m})$ & 300 \\
Width $(\mathrm{m})$ & 32 \\
Depth $(\mathrm{m})$ & 8.7 \\
Blocking coefficient $(-)$ & 0.7 \\
\hline
\end{tabular}

ter level for the whole period covered by the passage of the ship and in the whole modeled basin encompassing both the MVC and the tidal flat is produced. Time series of the water levels along Section-1 and Section-2 were extracted and used as forcing in the hydrogeological models.

A set of four scenarios was produced, considering a typical liner ship with the geometrical characteristics provided in Table 1 and moving in the system at $s=3.1,4.9,5.9$, and 7.7 knots. These velocity values cover a range from very low speeds, which are typical of in-port operations and manoeuvring, to speeds above the navigation limit (6 knots) typically measured in the channel and recorded in our AIS logs. The water level depression produced by the passage of the ship has a wide range of amplitudes, depending on $s$, and shows different behaviors approaching the tidal flat. As expected, the ship passage produces a depression whose maximum value increases with $s$ and decreases with the distance from the canal center (Table 2 and Fig. 6). Note that a cruise ship generates a depression wake that is almost half of that shown in Fig. 4 and produced by the Cargo-Hazard A when a comparable speed (i.e., 7.7 versus 8.1 knots) is assumed. The lateral depression is weakly (less than $20 \%$ ) attenuated within $100 \mathrm{~m}$ from the channel, in the close tidal flat, for the two highest speed values. At a distance of about $600 \mathrm{~m}$ from the channel, the height of the depression in the mudflat remains significant only for the $s=7.7$ knots case. For lower ship velocities, the residual signal over the mudflat is quite small.

\section{Modeling}

Short (from minutes to hours) and medium (i.e., months) term simulations addressing the effects of the tidal fluctuations and ship wakes have been carried out by a flow and transport uncoupled approach using subsurface modules FLOW3D and TRAN3D of the finite element CATchment HYdrology Flow-Transport (CATHY_FT) model (Camporese et al., 2010; Weill et al., 2011). The mixed hybrid finite element-finite volume COUPHYB simulator (Mazzia and Putti, 2006) for the solution of density-dependent flow and transport has been used to perform long-time (i.e., decades) analyses of seawater leakage into the aquifer system below the lagoon bottom.

The numerical simulations were carried out on 2-D vertical sections, in particular along Section-1 and Section-2 


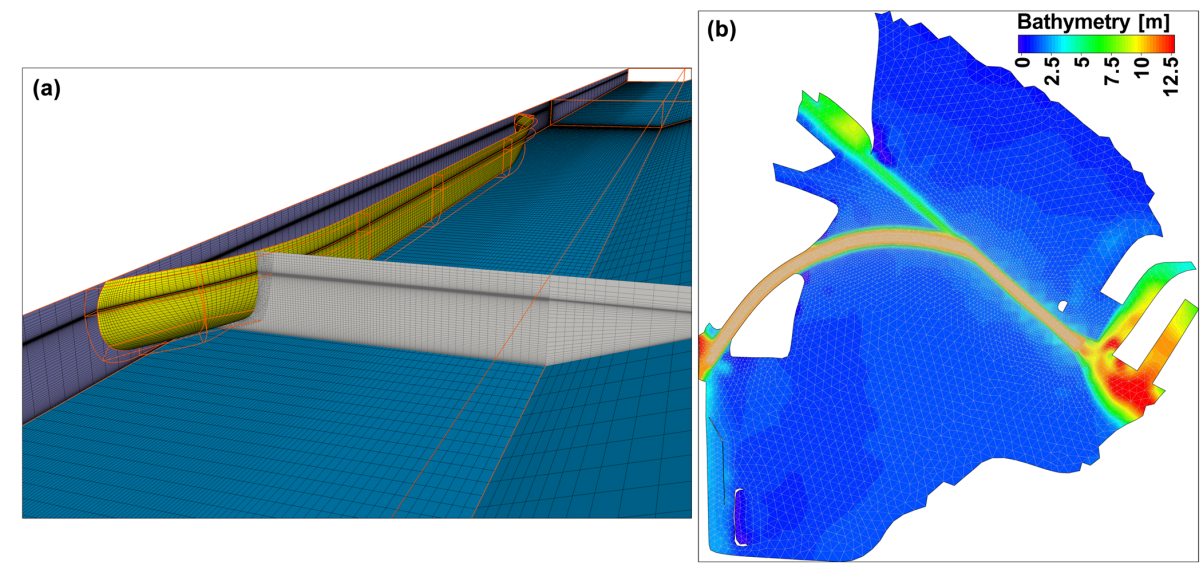

Figure 5. (a) Computational grid adopted in the uRaNSe-Xnavis simulations along the MCV. The figure shows the (coarse) grid over the ship hull (yellow), with the longitudinal symmetry plane shown in purple and the channel bottom in blue. (b) Finite element grid used in SHYFEM to represent the bathymetry of the Venice Lagoon portion where the MVC is expected to be dredged.

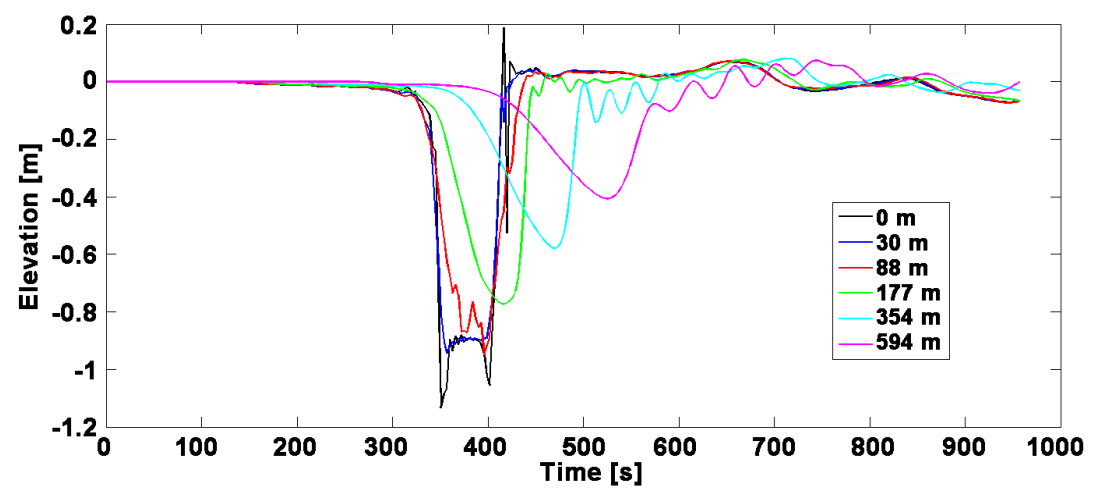

Figure 6. Water level behavior at various distances from the center of the MVC as computed by the hydrodynamic model for a liner ship moving at $s=7.7$ knots.

Table 2. Section-1: computed maximum depression $(\mathrm{m})$ in the MVC and percentage attenuation at various distances from the channel center for different speeds of the cruise ship. Similar values are obtained in Section-2.

\begin{tabular}{lrrrr}
\hline $\begin{array}{l}\text { Distance from } \\
\text { channel }(\mathrm{m})\end{array}$ & 3.1 knots & 4.9 knots & 5.9 knots & 7.7 knots \\
\hline 0 & $0.15 \mathrm{~m}$ & $0.3 \mathrm{~m}$ & $0.4 \mathrm{~m}$ & $0.9 \mathrm{~m}$ \\
30 & $-36.4 \%$ & $-19.1 \%$ & $-19.2 \%$ & $-16.5 \%$ \\
88 & $-40.6 \%$ & $-17.8 \%$ & $-19.7 \%$ & $-12.5 \%$ \\
177 & $-62.1 \%$ & $-44.5 \%$ & $-38.5 \%$ & $-31.8 \%$ \\
358 & $-68.5 \%$ & $-64.5 \%$ & $-54.0 \%$ & $-48.9 \%$ \\
594 & $-78.8 \%$ & $-74.6 \%$ & $-69.7 \%$ & $-64.1 \%$ \\
\hline
\end{tabular}

(Fig. 1b), which can be considered representative of the lagoon hydrogeological setting with respect to the MVC excavation. Indeed, the MVC bottom planned at $-10.5 \mathrm{~m}$ b.m.s.1. is bounded by an impermeable unit in Section-1 and is located in the middle of the sandy Aqf-1/2 in Section-2
(Fig. 7a). The effects of MVC were investigated by comparing the model results in the present (i.e., without the canal) and planned (i.e., with the canal) conditions. The model domains extend $600 \mathrm{~m}$ in the horizontal direction, for $300 \mathrm{~m}$ on each side of the MVC axis, and vertically from the lagoon bottom down to $-50 \mathrm{~m}$ a.m.s.l. Figure $7 \mathrm{~b}$ shows the triangular grid used to discretize Section-1. The distribution of the geologic layers as reconstructed in Fig. 2 was accurately reproduced within the model. The element size ranges from $0.5 \mathrm{~m}$ in the central zone around the MVC trace to $5.0 \mathrm{~m}$ in the outer portions. The nodes totalled about 18000 and 70000 in the present state and with the MVC, respectively, with approximately 35000 and 140000 triangles.

\subsection{Tidal and ship pressure fluctuations}

The evolution of the pressure and velocity fields in the shallow subsurface due to water level fluctuations in the lagoon was simulated by FLOW3D, neglecting the possible effects of different groundwater and surface water salinity. Indeed, 


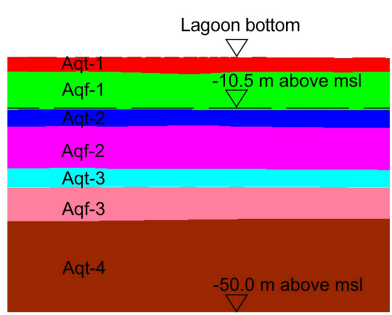

(a)

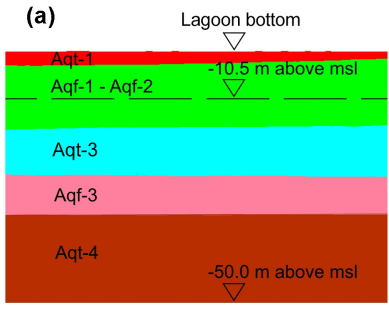

(b)

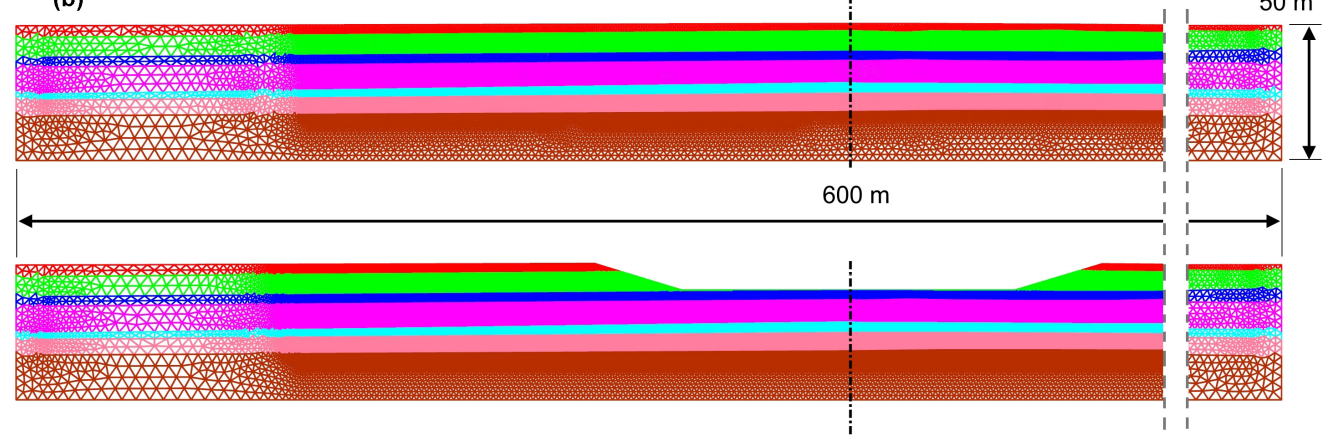

Figure 7. (a) Hydrogeological settings of Section-1 (above) and Section-2 (below) with respect to the MVC bottom. (b) Finite element mesh of Section-1 prior to (above) and after (below) the MVC excavation. The colors are representative of the various soil types.

density-driven processes are characterized by a much longer characteristic time than those typical of tidal regimes and ship wakes.

FLOW3D solves the groundwater flow equation in saturated conditions:

$\nabla \cdot[K \nabla h]=S_{\mathrm{s}} \frac{\partial h}{\partial t}+q$,

where $K$ and $S_{\mathrm{s}}$ are the saturated hydraulic conductivity $\left(\mathrm{L} \mathrm{T}^{-1}\right)$ and the specific elastic storage $\left(\mathrm{L}^{-1}\right)$ of the porous medium, respectively, $h=z+p /\left(\rho_{0} g\right)=z+\psi$ is the hydraulic head $(\mathrm{L}), z$ is the vertical coordinate directed upward $(\mathrm{L}), p$ is the pressure $\left(\mathrm{ML}^{-1} \mathrm{~T}^{-2}\right), \rho_{0}$ is the freshwater density $\left(\mathrm{ML}^{-3}\right), g$ is the gravitational acceleration $\left(\mathrm{L} \mathrm{T}^{-2}\right), t$ is the time (T), $q$ is a source or sink term $\left(\mathrm{L}^{3} \mathrm{~L}^{-3} \mathrm{~T}^{-1}\right)$, and $\nabla$ is the gradient operator $\left(\mathrm{L}^{-1}\right)$. In FLOW3D Eq. (1) is solved using linear Galerkin finite elements (FEs), with triangular elements and a weighted finite difference time integration scheme (Paniconi and Putti, 1994).

FLOW3D was initially used to calibrate the hydrogeologic properties of the upper units. This was carried out by running the model in the present configuration and matching the pressure records available at the two $10 \mathrm{~m}$ deep piezometers. Dirichlet conditions representing the observed tidal regime over spring 2016 were imposed on the top boundary, which constitutes the lagoon bottom; a constant head $h=0.5 \mathrm{~m}$ a.m.s.l., i.e., the average water level over the monitoring period, is prescribed on the lateral bounds, and zero flux through the bottom. The $K$ and $S_{\mathrm{s}}$ obtained by the calibration for Aqt-1 and Aqf-1 are presented in Table 3. They are in good agreement with values obtained in previous modeling studies carried out in the Venice area (Castelletto et al., 2015; Paris et al., 2011) and hence used to also characterize the deeper layers.
Table 3. Hydrogeological parameters obtained by the model calibration and used in the numerical simulations. Aqt-2 is lacking in Section-2.

\begin{tabular}{ccc}
\hline Layer & $K\left(\mathrm{~m} \mathrm{~s}^{-1}\right)$ & $S_{\mathrm{S}}\left(\mathrm{m}^{-1}\right)$ \\
\hline Aqt-1 & $1.7 \times 10^{-6}$ & $5.0 \times 10^{-4}$ \\
Aqf-1 & $1.0 \times 10^{-5}$ & $2.0 \times 10^{-5}$ \\
Aqt-2 & $1.0 \times 10^{-7}$ & $5.0 \times 10^{-4}$ \\
Aqf-2 & $1.0 \times 10^{-5}$ & $2.0 \times 10^{-5}$ \\
Aqt-3 & $1.0 \times 10^{-7}$ & $5.0 \times 10^{-4}$ \\
Aqf-3 & $1.0 \times 10^{-5}$ & $2.0 \times 10^{-5}$ \\
Aqt-4 & $1.0 \times 10^{-7}$ & $5.0 \times 10^{-4}$ \\
\hline
\end{tabular}

The calibrated model was then used to quantify the effect of the MVC in terms of pressure and flow field on the subsurface in relation to

- tidal regime: the same boundary conditions used for the model calibration were applied on the domain with the MVC and the results obtained with the two configurations were compared. The simulations were carried out using a time step $\Delta t=360 \mathrm{~s}$.

- Ship wakes: we investigate the effects induced by both the commercial vessel of Fig. 4, which represents an extreme of the perturbations possibly stressing the system, and a cruise vessel with $s=7.7$ knots. The initial conditions were derived from the FLOW3D outcome obtained in the previous simulations investigating the tidal regime. The boundary conditions are represented by the measured (Fig. 4) and simulated (Fig. 6) water levels for the nodes corresponding to the MVC bottom and slopes. The results of the SHYFEM model at a distance of $300 \mathrm{~m}$ from the MVC were used to fix the behavior of 
the water level for the nodes on the lateral boundaries. A linear interpolation, both in space and in time, between the canal and the $300 \mathrm{~m}$ aside values was used to derive the water level on the nodes located on the tidal flats. Similar to the previous case, the bottom boundary was assumed to be impermeable. The ships transit after $2700 \mathrm{~s}$ (approximately $45 \mathrm{~min}$ ) from the inception of the simulation, which spans a total time equal to $3000 \mathrm{~s}$ using $\Delta t=1 \mathrm{~s}$.

\subsection{Contaminant transport}

Transport processes in the subsurface of non-reactive chemicals are described by the classical advection-dispersion equation (Bredehoeft and Pinder, 1973):

$\nabla \cdot[D \nabla c-v c]=\varphi \frac{\partial c}{\partial t}-q_{c}$,

where $D$ (Bear, 1979) is the dispersion tensor accounting for both mechanical dispersion and molecular diffusion $\left(\mathrm{L}^{2} \mathrm{~T}^{-1}\right), c$ is the subsurface solute concentration $\left(\mathrm{ML}^{-3}\right)$, $v$ is the Darcy velocity vector $\left(\mathrm{L} \mathrm{T}^{-1}\right), \phi$ is the porosity (), and $q_{c}$ is a term incorporating an external solute sink or source $\left(\mathrm{ML}^{-3} \mathrm{~T}^{-1}\right)$.

Similarly to FLOW3D, TRAN3D solves Eq. (2) using a Galerkin FE approach and a weighted finite difference time integration scheme (Gallo et al., 1996). TRAN3D was used to quantify the possible exchange of the contaminants detected in the subsurface between the groundwater and the surface waters along the MVC trace. In particular, attention was focused at the ship wakes that, being strongly asymmetric, favor the contaminant outflow into the lagoon waters much more than the tide fluctuations, which are almost symmetric with respect to the mean sea level. The velocity field at each time step is provided by the outcome of FLOW3D. Based on the general outcome of the chemical characterization, the following simplifying assumptions were adopted in the modeling setup.

- $c$ represents the concentration of the sole labile and bioaccessible fraction, i.e., the contaminant portion that can be reasonably assumed to be in equilibrium with the concentration in the groundwater.

- The $c$ values measured at the two wellbores are representative of the initial contaminant distribution within the whole modeling domains.

- Table 4 provides the $c$ values averaged between the depth range from -10 to $-5 \mathrm{~m}$ b.m.s.l. These concentrations were assumed to be uniformly distributed within Aqf-1 (Section-1) and Aqf-1/2 (Section-2). Based on the available data, in Aqt-1 $c$ can be grossly assumed to be equal to $20 \%$ of the value in the underlying aquifer. This $c$ distribution is used as an initial condition in the transient transport simulations.
Table 4. Average contaminant concentration (labile fraction) in the depth range between -9 and $-5 \mathrm{mb}$.m.s.l. in Section- 1 and Section-2.

\begin{tabular}{lrr}
\hline Contaminant & $\begin{array}{r}c\left(\mathrm{mg} \mathrm{L}^{-1}\right) \\
\text { Section-1 }\end{array}$ & $\begin{array}{r}c\left(\mathrm{mg} \mathrm{L}^{-1}\right) \\
\text { Section-2 }\end{array}$ \\
\hline $\mathrm{Hg}$ & 0.03 & 0.01 \\
$\mathrm{Cd}$ & 0.08 & 0.04 \\
$\mathrm{~Pb}$ & 0.99 & 0.30 \\
$\mathrm{As}$ & 0.47 & 0.17 \\
$\mathrm{Cr}$ & 0.88 & 0.68 \\
$\mathrm{Cu}$ & 0.59 & 0.14 \\
$\mathrm{Ni}$ & 0.35 & 0.72 \\
$\mathrm{Zn}$ & 1.50 & 1.03 \\
$\mathrm{Se}$ & 0.40 & 0.04 \\
$\mathrm{~V}$ & 0.67 & 0.90 \\
$\mathrm{Sb}$ & 0.02 & 0.01 \\
\hline
\end{tabular}

- $c=0$ below Aqf-1 in Section-1 and Aqf-1/2 in Section2; i.e., Aqt-2 precludes the anthropogenic contamination at larger depths.

The simulations were carried out by normalizing the actual $c$ values with respect to the initial concentrations in the shallower aquifer. This allowed us to run the transport model independently of the specific contaminant, with the quantification of the actual concentration in the subsoils and mass expelled into the lagoon carried out a posteriori for each species multiplying the modeling outcome by the values provided in Table 4 . A value $c=0$ has been imposed on the top boundary, i.e., the concentration of the metals in the lagoon water has been assumed to be negligible, with $\partial c / \partial n=0$ along the lateral and bottom boundaries. Due to the lack of specific information, a proper sensitivity analysis was carried out of the longitudinal $\left(\alpha_{\mathrm{L}}\right)$ and transversal $\left(\alpha_{\mathrm{T}}\right)$ dispersivity $(\mathrm{L})$, which defines the dispersion tensor $D$ (Bear, 1979). In particular, a value of $\alpha_{\mathrm{L}}$ ranging from 0.1 to $10 \mathrm{~m}$ has been evaluated, with the ratio $\alpha_{\mathrm{L}} / \alpha_{\mathrm{T}}$ varying from 0.1 to 1 . Table 5 summarized the investigated scenarios.

The transport process was investigated over a multiple ship passage. Specifically, the transit of $N_{\mathrm{v}}=1000$ vessels was simulated by concatenating the relative FLOW3D outcome 1000 times. According to the information available from the Venice Port Authority and summarized in the introduction, this simulation should represent a period of approximately 1 year.

\subsection{Density-dependent interactions}

As reported above, the available hydrogeological investigations revealed that the subsurface of the Venice Lagoon is characterized by significant stratification in terms of water salinity, reflecting the layering of the sedimentary sequence. Dredging of new canals in such an environment can cut impermeable units, producing a certain mixing of the salt con- 
Table 5. Longitudinal $\left(\alpha_{\mathrm{L}}\right)$ and transversal $\left(\alpha_{\mathrm{T}}\right)$ dispersivity for the scenarios investigated with TRAN3D.

\begin{tabular}{lrr}
\hline Scenario & $\alpha_{\mathrm{L}}(\mathrm{m})$ & $\alpha_{\mathrm{T}}(\mathrm{m})$ \\
\hline Base & 1 & 0.1 \\
Scenario1 & 1 & 1 \\
Scenario2 & 10 & 1 \\
Scenario3 & 0.1 & 0.1 \\
\hline
\end{tabular}

centration between the shallowest contaminated units and the fresher underlying layers. Due to the lack of a significant pressure gradient between the various geologic layers, the difference in groundwater density is likely the main driver of salt transport.

Following Bear (1979), the mathematical model of density-dependent flow in aquifer systems can be written using the equivalent freshwater pressure head $\psi$ and the salt concentration normalized with respect to its maximum value $c$. Defining the density $\rho$ and the dynamic viscosity $\mu$ of the saltwater through the reference density $\rho_{0}$ and dynamic viscosity $\mu_{0}$,

$\rho=\rho_{0}(1+\varepsilon c)$,

$\mu=\mu_{0}\left(1+\varepsilon^{\prime} c\right)$,

where $\varepsilon=\left(\rho_{\mathrm{s}}-\rho_{0}\right) / \rho_{0}$ and $\varepsilon^{\prime}=\left(\mu_{\mathrm{s}}-\mu_{0}\right) / \mu_{0}$, with $\rho_{\mathrm{s}}$ and $\mu_{\mathrm{s}}$ the density and viscosity of the solution at $c=1$, respectively; the equations of mass conservation for the coupled flow and transport model in porous media can be written as

$$
\begin{gathered}
\nabla \cdot\left[K \frac{1+\varepsilon c}{1+\varepsilon^{\prime} c}\left(\nabla \psi+(1+\varepsilon c) \eta_{z}\right)\right]= \\
\sigma \frac{\partial \psi}{\partial t}+\varphi \varepsilon \frac{\partial c}{\partial t}+\frac{\rho}{\rho_{0}} q^{*}+q, \\
\boldsymbol{v}=-K \frac{1+\varepsilon c}{1+\varepsilon^{\prime} c}\left[\nabla \psi+(1+\varepsilon c) \eta_{z}\right], \\
\nabla \cdot[D \nabla c-\boldsymbol{v} c]=\varphi \frac{\partial c}{\partial t}-q c^{*} .
\end{gathered}
$$

In Eq. (5), $\sigma=S_{\mathrm{S}}(1+\varepsilon c)$ is the general storage term, the vector $\eta_{z}$ is equal to 0 along the $x$ and $y$ directions and to 1 along the $z$ direction, $q^{*}$ is the injected and $q$ the withdrawn volumetric flow rate, and $c^{*}$ is the normalized concentration of salt in the injected/extracted fluid.

In the COUPHYB simulator (Mazzia and Putti, 2006), the system (5) is solved numerically using a mixed hybrid finite element scheme for the flow equation and a mixed hybrid finite element-finite volume time-splitting-based scheme for the transport equation. This approach is computationally effective and accurate, introducing minimal numerical diffusion even in the absence of physical dispersion, and when the process is advection dominated or density changes yield instabilities in the flow field. COUPHYB was applied to the same triangulation shown in Fig. 7b, with the solutions in terms of $\psi$ and $c$ provided on the mesh elements and in terms of $\boldsymbol{v}$ on the element faces, which amount to about 60000 and 200000 in the present state and with the MVC, respectively.

Based on the hydrogeological information, the simulations were carried out starting from an initial $c$ distribution where the first buried clay layer (Aqt-2 in Section-1 and Aqt-3 in Section-2) prevented the downward propagation of the saltier water. Therefore, $c=0$ and $c=0.7$ below and above the top of the sealing layer, respectively. The latter value was obtained based on the data published in Teatini et al. (2011). Concerning the boundary conditions, $\partial c / \partial n=0$ was prescribed along the lateral and bottom boundaries, with $c=1$, i.e., the seawater concentration, imposed on the nodes corresponding to the lagoon and MVC bottom. For the flow equation, the bottom was considered impermeable and a constant tidal level equal to $0.5 \mathrm{~m}$ a.m.s.l. is assumed in the lagoon. The $\psi$ values on the top and lateral boundaries were computed in agreement with the $c$ initial distribution and using $\rho_{\mathrm{s}} / \rho_{0}=1.035(\varepsilon=0.035)$. Moreover, $\varepsilon^{\prime}=0.231, \alpha_{\mathrm{L}}=$ $1.0 \mathrm{~m}$ and $\alpha_{\mathrm{T}}=0.1 \mathrm{~m}$ were assumed. The simulations covered a time interval equal to 10 years.

\section{Results}

\subsection{Tidal effects}

The dredging of a new relatively deep channel in a tidal environment can perturb the natural pressure and flow fields in the shallow subsurface. Quantification is obtained by comparing the results provided by the calibrated FLOW3D for the two simulated sections in the present condition and after the MVC excavation. Figure 8 shows the behavior of the pressure at a depth of $13 \mathrm{~m}$ b.m.s.l. in correspondence to the MVC symmetry axis. The point is located within Aqt-2 and Aqf-1/2 in Section-1 and Section-2, respectively. The effect of the different stratigraphic sequence is obvious, with an approximately $85 \%$ reduction of the pressure fluctuation within the clayey layer with respect to the oscillation of the lagoon level (Fig. 8a). The MVC dig reduces the time lag and the attenuation of the perturbation at depth. These effects are quantitatively negligible and develop only in the surroundings of the channel (Fig. 9).

\subsection{Ship-wake effects}

Although a depression wave caused by a ship transit develops over a period of a couple of minutes (Figs. 4 and 6), which usually is a very short time for hydrogeological processes, its height is sufficient to affect significantly the groundwater pressure and flow fields in the proximity of the channel bottom.

Figure 10 provides the pressure distribution in the surroundings of the MVC, Section-2, computed by FLOW3D at the significant time steps highlighted in Fig. 4 during the transit of the Cargo-Hazard A. The pictures clearly show how 

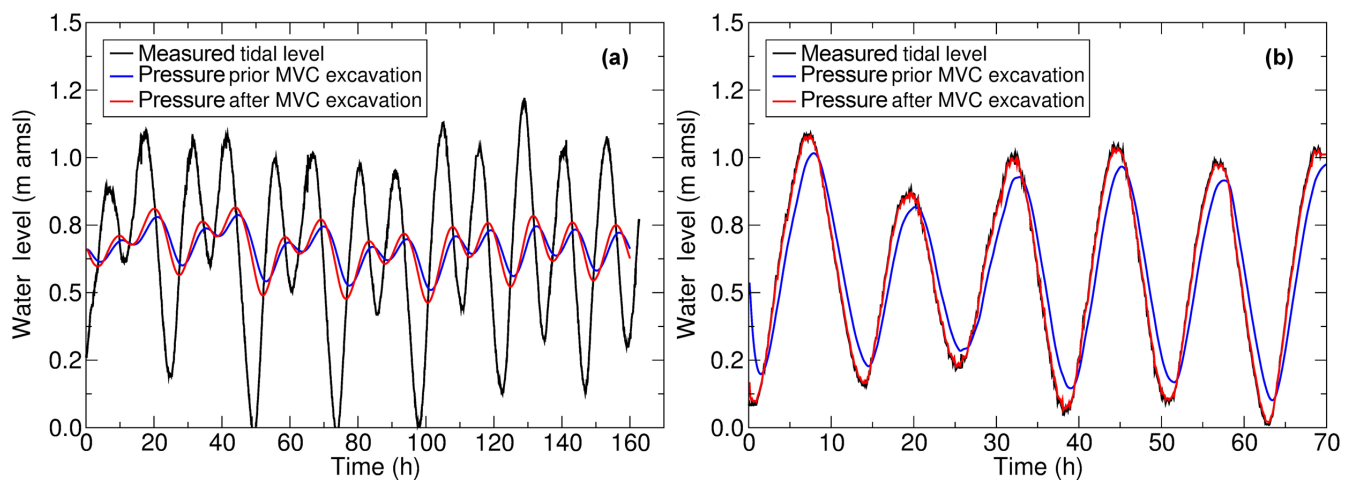

Figure 8. Behavior versus time of the pressure at a depth of 13 mb.m.s.l. in (a) Section-1 and (b) Section-2, respectively, prior to and after the MVC excavation. The tide fluctuation is provided for comparison.

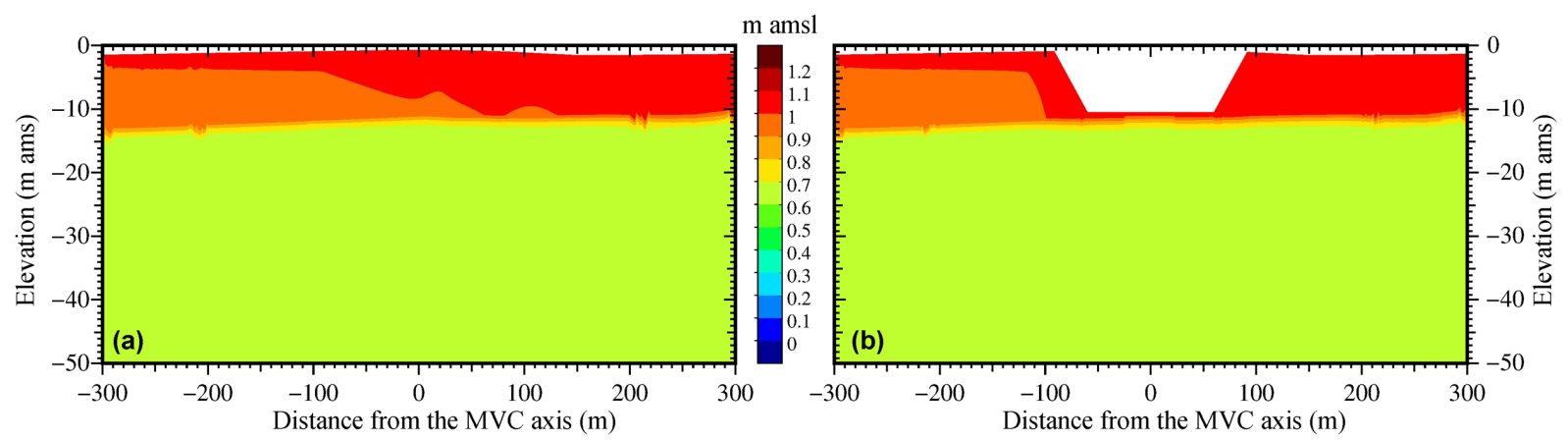

Figure 9. Section-1: computed pressure distribution (a) prior to and (b) after the MVC excavation at the maximum tidal level highlighted in Fig. 8. Vertical exaggeration is 8 .

the pressure gently rises before the ship passage, significantly decreases soon after the transit, and then recovers with a gradient that changes its sign during each phase. The pressure change affects the portion of the subsoil down to the top of the first clay layer below the channel bottom, and extends laterally up to about $30 \mathrm{~m}$ from the channel slope (Fig. 11a and $b$ for Section-1 and Section-2, respectively). The typically short duration of such events precludes the propagation of the pressure change far from the channel edges. The velocity field in correspondence to the maximum depression is provided in Fig. 11c and d. The ship generates a sort of "piston effect" with an efflux distributed along the whole channel bottom and slope. The maximum values of the velocity amount to $1.1 \times 10^{-5} \mathrm{~m} \mathrm{~s}^{-1}$ and $0.6 \times 10^{-5} \mathrm{~m} \mathrm{~s}^{-1}$ for Section1 and Section-2, respectively. The highest velocities are computed in Section-1 due to the vicinity of the Aqt-2 top to the MVC bottom, and the consequent pressure gradient is much larger than in Section-2.

The seepage from the MVC bottom and slope (between times T2 and T4 in Fig. 10) amounts to $3.25 \times 10^{-2} \mathrm{~m}^{3}$ and $2.63 \times 10^{-2} \mathrm{~m}^{3}$ per meter length of the channel for Section1 and Section-2, respectively. Considering the total length of approximately $3 \mathrm{~km}$, each commercial vessel produces a cumulative groundwater volume flowing into the MVC to- talling $\sim 100$ or $\sim 80 \mathrm{~m}^{3}$ assuming Section-1 or Section2 , respectively, as representative of the lagoon subsurface. Therefore, a value of about $90 \mathrm{~m}^{3}$ can be estimated on average.

The same computation was carried out for the ship wake caused by a cruise ship moving at 7.7 knots. The results provided by the hydrodynamic model (Fig. 6) were used to force FLOW3D. The computed subsurface pressure and velocity fields are qualitatively similar to those previously described (Figs. 10 and 11), with smaller values determined by the lower wave height used as a forcing factor. The average efflux along the whole MVC decreases to $\sim 45 \mathrm{~m}^{3}$ per ship transit.

The effect of the transit of several ships along the MVC in terms of contaminant release from the subsurface into the lagoon was investigated through TRAN3D. The behavior of the released mass $m^{*}$ versus the number of transits is shown in Fig. 12. For each of the two sections, the figure provides the model outcome for the various scenarios (Table 5) and the two vessels (the cargo and cruise ships) addressed by the simulations. The largest mass seepage occurs at the beginning, and then decreases due to the $c$ reduction in the volume surrounding the channel bottom and slopes (Fig. 13). Scenario-1 does not differ appreciably from the Base scenario, suggest- 

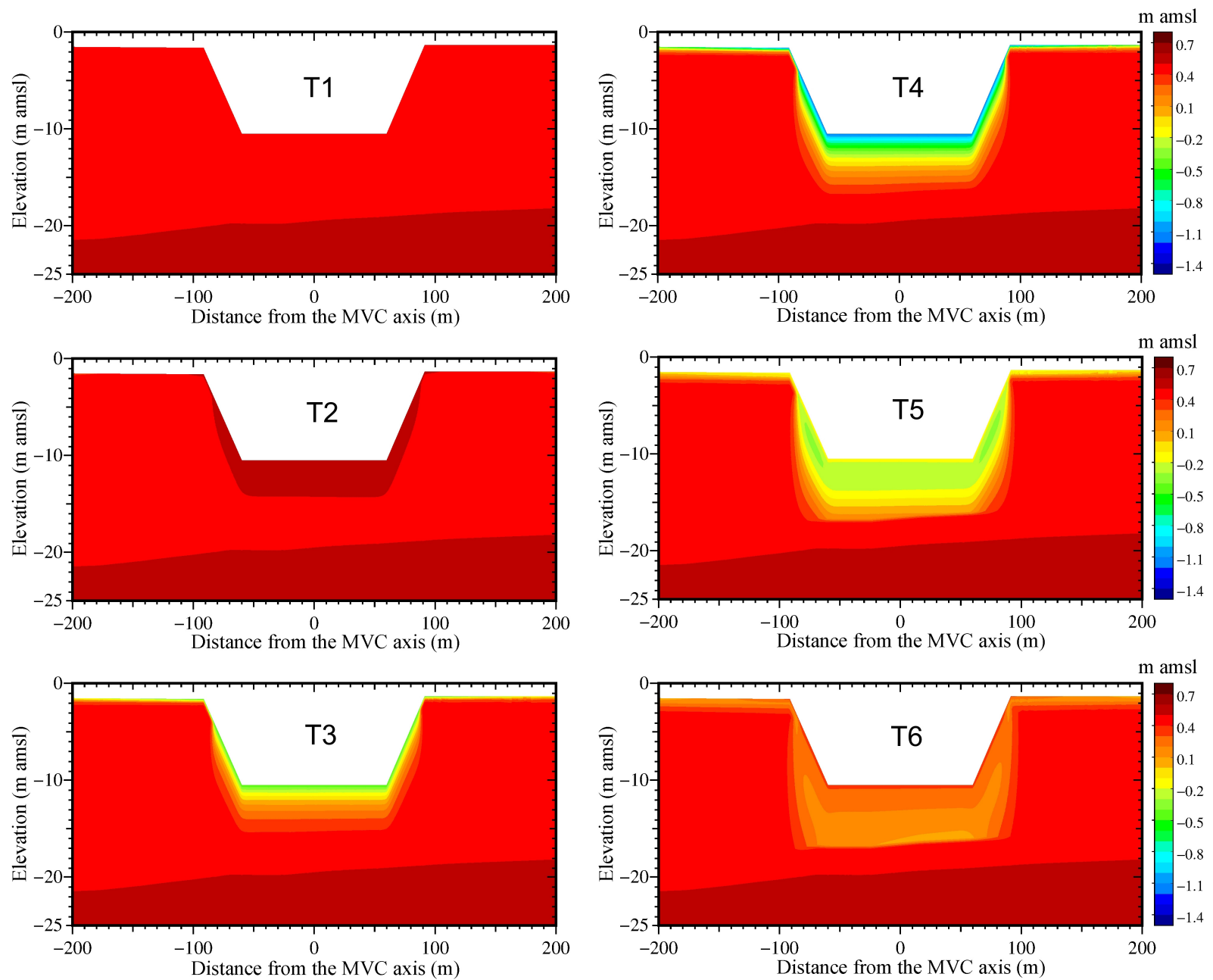

Figure 10. Section-2: computed pressure distribution at the times T1-T6 highlighted in Fig. 4 during the transit of the Cargo-Hazard A. The vertical exaggeration is 8 .

ing a negligible effect of the transversal dispersivity. Note that, although the maximum groundwater velocities were computed in Section-1, $m^{*}$ is larger (by 1.9 to 3.5 times) in Section-2 independently of the dispersivity scenario because of the larger subsurface volume, with significant velocity values in the latter (Fig. 11c and d). Table 6 summarizes the ratio between the expelled mass at $N_{\mathrm{v}}=1000$ as obtained with Scenario-1-Scenario-3 and the reference values provided by the Base case. Decreasing and increasing $\alpha_{\mathrm{L}}$ by 1 order of magnitude yields a reduction and rise in $m^{*}$ in the ranges of $20-40$ and $220-370 \%$, respectively.

Combining the actual initial concentration of the various anthropogenic contaminants (Table 4) and the TRAN3D outcomes allows estimation of the real mass $m$ of each contaminant released into the lagoon. Figure 14 shows the behavior of $m$ versus the number of ship transits. The profiles have been obtained by averaging the outcomes obtained for Section-1 and Section-2 and using a MVC length equal to $3 \mathrm{~km}$.
Table 6. Ratio between the reference mass $m^{*}$ expelled from the subsurface into the MVC after a transit of 1000 ships for the various scenarios addressed by the study.

\begin{tabular}{llrr}
\hline Scenario & Ship & \multicolumn{2}{c}{ Section } \\
\cline { 3 - 4 } & & Section-1 & Section-2 \\
\hline Scenario-1/Base & Cargo & 1.01 & 1.01 \\
& Cruise & 1.01 & 1.00 \\
Scenario-2/Base & Cargo & 2.28 & 3.35 \\
& Cruise & 2.34 & 3.70 \\
Scenario-3/Base & Cargo & 0.39 & 0.22 \\
& Cruise & 0.35 & 0.18 \\
\hline
\end{tabular}

\subsection{Aquifer salinization}

Figure 15 shows the outcome of COUPHYB in terms of relative concentration at the end of the simulation period, i.e., 10 years after the inception. The results are presented for 

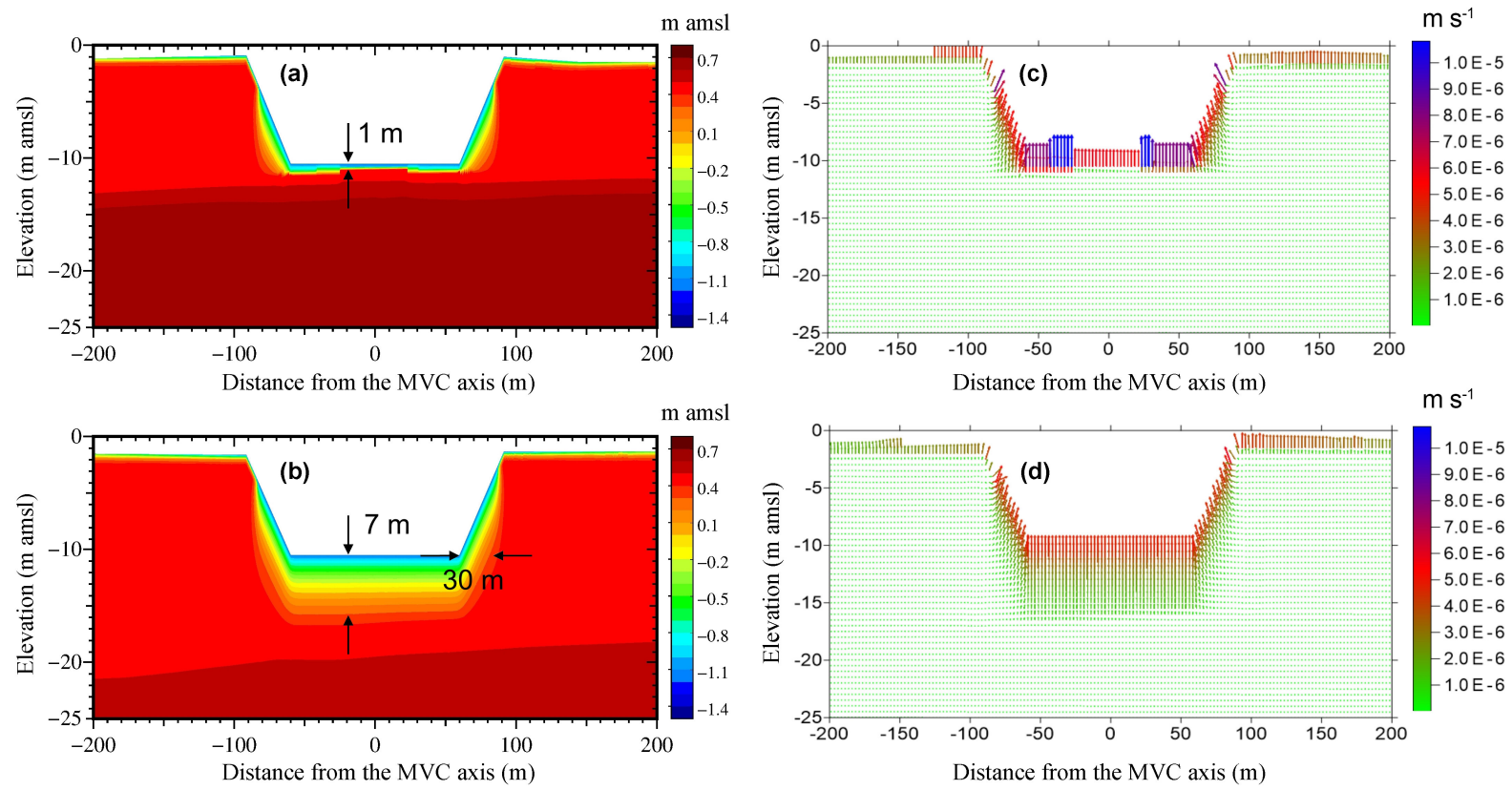

Figure 11. Computed (a, b) pressure distribution and (c, d) velocity field at the maximum wake induced by the Cargo-Hazard A transit in (a, c) Section-1 and (b, d) Section-2. The dimensions of the subsurface portion feeling the ship transit are highlighted in panels (a) and (b). Vertical exaggeration is 8 .

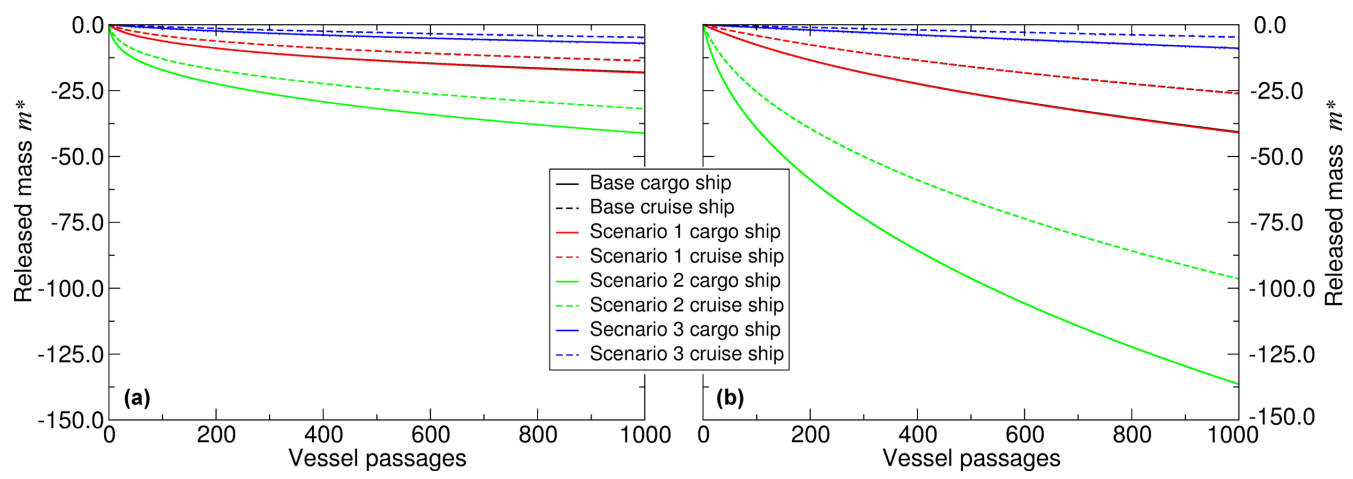

Figure 12. Behavior of $m^{*}$ as computed by TRAN3D in (a) Section-1 and (b) Section-2, respectively, for the different dispersivity scenarios and the two ship types addressed by the simulations.

both the sections addressed by the study. The effect of the MVC excavation is pointed out by comparing the two settings, i.e., the present condition and that where the MVC is dredged. Cutting the top clayey layer, the excavation favors the propagation at depth of the seawater, with an increase in $c$ from the initial 0.7 value to more than 0.9 in the surroundings of the canal. The salt propagation downward is more pronounced in Section-2 than in Section- 1 because of the Aqt-2 presence directly below the MVC bottom in the latter. Note that the increased contamination remains located in the surroundings of the channel excavation, with Aqt-3 completely precluding the salt transport at larger depth.

\section{Discussion}

\subsection{Model limitations}

We are aware that the analyses presented here rely on a number of simplifications, with results that can be affected by (1) the approximated modeling approach used for the simulations, (2) the representativeness of the hydrologic and geological information used to calibrate the model parameters, and (3) the boundary conditions and the factors forcing the system (Tsang, 2005).

In this study, we have elected to use a 2-D modeling approach along vertical sections instead of a 3-D analysis. The choice is warranted by the shape of the domain possibly in- 


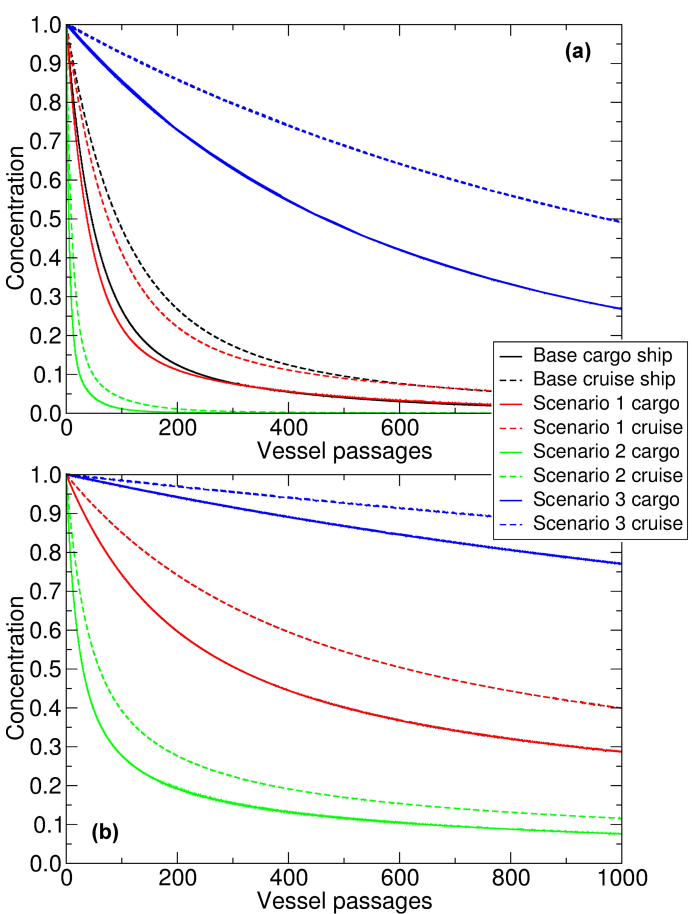

Figure 13. Section-2: behavior of $c$ for a node located $0.5 \mathrm{~m}$ below the MVC bottom along the symmetry axis as computed by TRAN3D in (a) Section-1 and (b) Section-2, respectively, for the different dispersivity scenarios and the two ship types addressed by the simulations.

fluenced by the excavation, which is much more elongated along the MVC trace than in the orthogonal direction. Moreover, the groundwater flow induced by a ship moving along the canal, which represents the main factor forcing the system in the short and medium term, is characterized by a net component along the direction orthogonal to the ship track only. The two selected sections are representative of the main variability characterizing the hydrogeological architecture of the Venice Lagoon subsurface. Several boreholes drilled in the past and the extensive seismic survey carried out during the initial phase of the study provided an accurate characterization of the shallowest $50 \mathrm{~m}$ thick depositional sequence and revealed that, although local sedimentary anomalies are frequently encountered, the presence of a buried large channelling system cutting Aqt- 2 in a specific portion of the study area is the main feature to be accounted for in the modeling investigations.

A critical issue is related the calibration of the hydrogeological parameters $\left(K, S_{\mathrm{s}}, D\right)$. The model calibration has been conducted using trial-and-error (Anderson et al., 2015) and relies on the piezometric records collected at two boreholes, one per section, penetrating the MVC depth of excavation. We are aware of the non-uniqueness of this solution and the paucity of the data that do not support it, for example, to account for a possible spatial variation of the parame- ters. Concerning $K$, an isotropic porous medium has always been assumed in the simulations described above. Two reasons support the choice to neglect anisotropy: firstly, the shallow depth of interest that reduces the effect of the geostatic load in decreasing $K$ along the vertical direction (Whipkey and Kirkby, 1978); secondly, bioturbation that enhances the "original" hydraulic conductivity of sedimentary units along the vertical direction. Such activities are typically limited to less than a meter in depth (Gerino et al., 2007), but can affect large thicknesses in highly dynamic coastal depositional environments (Gingras et al., 2015). However, note that a precise calibration of the model is beyond the scope of the study. Indeed, the principal goal is to investigate which are the main processes affecting a lagoon subsurface caused by a deep excavation and transit of large ships through a shallow tidal flat.

Concerning the transport model, a sensitivity analysis of $\alpha_{\mathrm{L}}$ and $\alpha_{\mathrm{T}}$ has been carried out. Due to the lack of specific dispersion and tracer tests, the amount of contaminants released from the shallow sediments into the lagoon has been quantified versus the $\alpha_{\mathrm{L}}$ and $\alpha_{\mathrm{T}}$ values. In this first analysis, the transport simulations have been focussed only on the labile fraction of the contaminants, thus supporting the use of a non-reactive transport model. The spatial and depth variability of the initial contaminant concentrations has been properly characterized in 11 boreholes, continuously cored along the MVC trace (Fig. 1).

Finally, the simulations have been carried out assuming a null natural flow due to the lack of specific information. Because of the shallow depth of investigation and the position of the study area at the edge of the flat Po Plain, the natural hydraulic gradient is certainly very small. Therefore, the results of the short- and mid-term simulations are almost unaffected by the assumption.

\subsection{Main insights}

Lagoons are natural environments that undergo a continuous increase in anthropogenic pressure. On the other hand, their present hydraulic and morphologic equilibrium is in some cases artificially preserved by human interventions, which are aimed at contrasting the combined effects of sea level rise associated with global warming and land subsidence of natural and anthropogenic origin.

The Lagoon of Venice is a paradigm of the complexity in the interactions among economic, social, and environmental needs (Rinaldo, 2001). This holds for both the surface and subsurface environments. Investigations carried out over recent years (Teatini et al., 2011; Viezzoli et al., 2010) revealed that fresh groundwater resources are found at quite low depths, i.e., $30-40 \mathrm{~m}$ and even less than $10 \mathrm{~m}$ beneath the lagoon bottom. Like the hydrogeological settings of other lagoons (e.g., Santos et al., 2008), the silty-clayey layer marking the boundary between the marine Holocene and continental Pleistocene deposits precludes or at least reduces the vertical leakage of the salt waters downward into the un- 

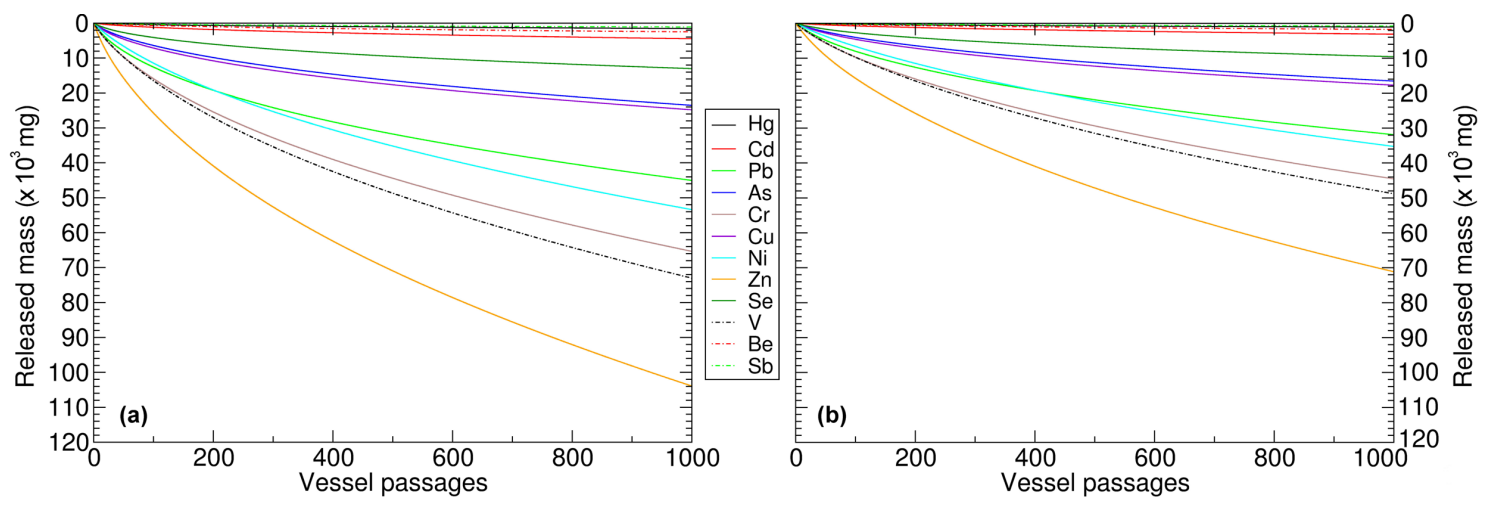

Figure 14. Mass of various chemicals expelled from the lagoon subsurface through the MVC bottom versus the transit number of (a) cargo and (b) cruise ships.
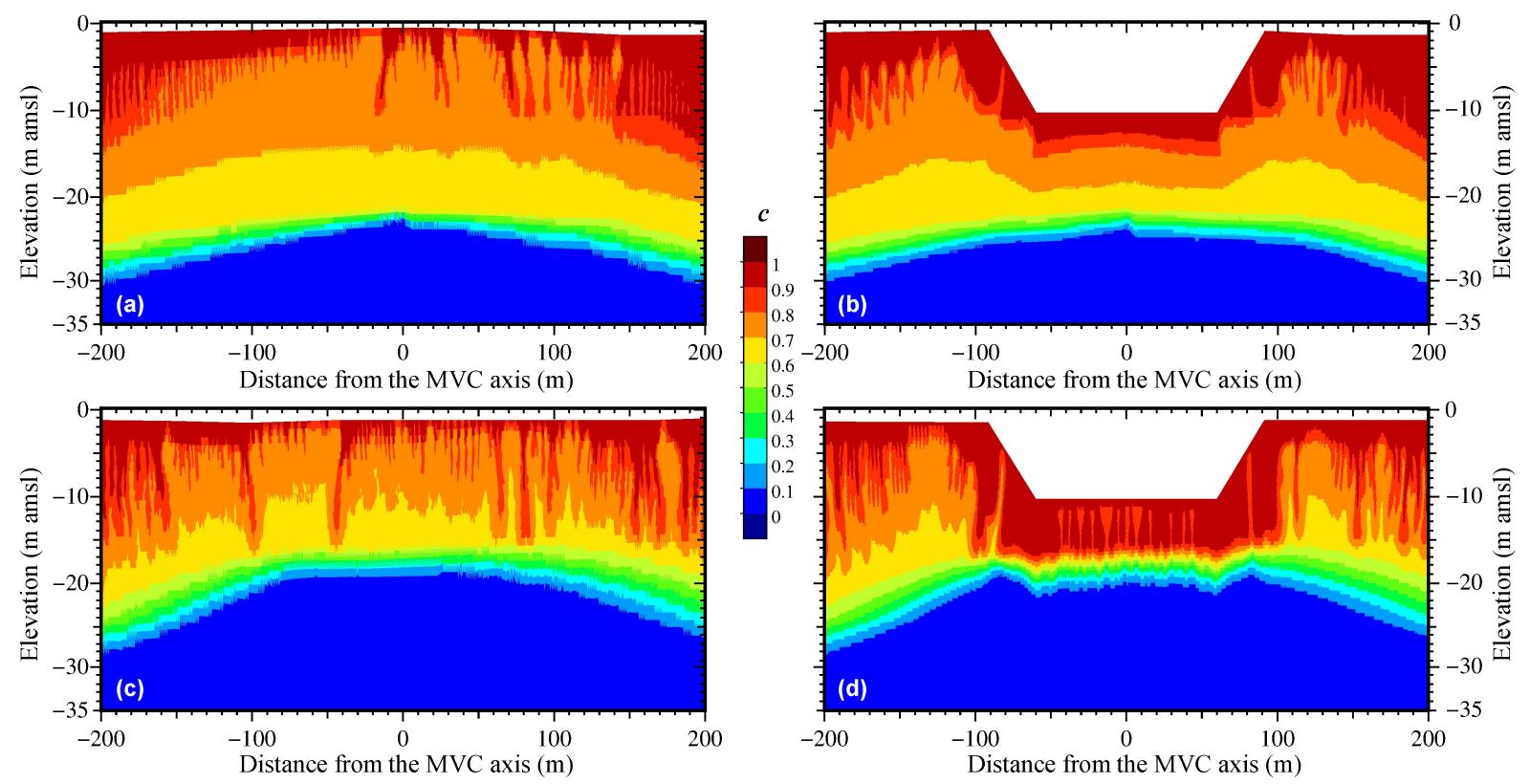

Figure 15. Relative salt concentration in (a, c) initial conditions and (b, d) after 10 years as computed in (a, b) Section-1 and (c, d) Section-2 in the present $(\mathbf{a}, \mathbf{c})$ and planned $(\mathbf{b}, \mathbf{d})$ conditions, respectively. Vertical exaggeration is 12.

derlying freshwater aquifers. However, a large petrochemical industrial district, the PMIZ, has been in operation since the 1950s at the lagoon-mainland interface, representing the main source of soil and water pollution around the area (e.g., Zonta et al., 2007). Despite an almost $50 \mathrm{~km}$ long cut-off wall built up along the canal banks of the PMIZ to prevent discharge of contaminated waters into the lagoon (Paris et al., 2011), results from chemical analyses provided evidence of a high content of $\mathrm{Hg}, \mathrm{Zn}$, and other metals in the bottom sediments and pore water not only in front of the industrial site (Gieskes et al., 2015), but also at distance. Although quite gentle in the shallower subsurface, the natural groundwater flow from the mainland seaward has likely transported the contaminants to the lagoon ecosystem over the last decades.
The quality of an aquatic ecosystem is set by the quality of its sediments. Sediments are a sink for pollutants and nutrients, but can also act as a long-term source as well, with the groundwater playing a key role in the redistribution of hazardous substances in other environmental compartments, such as the biota, upon changes in the physical-chemical conditions. Similarly to other coastal lagoons with an inner port and/or an industrial zone, for example the Maryut Lagoon, Nile Delta (Oczkowsly and Nixon, 2010), or Lake Macquarie, New South Wales, Australia (Thomsen et al., 2009), anthropogenic contaminants have been detected in the Venice Lagoon subsurface.

Cutting of the clayey layers that characterize the shallower Pleistocene and Holocene deposits in coastal zones can sig- 
nificantly increase the exchange between groundwater and surficial water bodies and the anthropogenic and/or natural contaminants transported with the waters. For example in the Mangueira Lagoon, which is a large ( $90 \mathrm{~km}$ long), shallow ( 4-5 m deep), fresh, and non-tidal coastal lagoon in southern Brazil surrounded by extensively irrigated rice plantations and numerous irrigation channels, the use of naturally geochemical tracers $\left({ }^{222} \mathrm{Rn},{ }^{223} \mathrm{Ra}, \delta^{18} \mathrm{O}, \delta^{2} \mathrm{H}\right.$, and others) showed that dredging of irrigation channels altered the SGD fluxes (Santos et al., 2008). In spite of the relatively small depth and dimension of the channels, the ditch digging cut the shallow aquitards, which previously restricted the upward advection from the permeable strata underlying the lagoon bottom, increasing the fluxes of contaminants into the lagoon.

The evaluation of the possible impacts of the MVC excavation must be investigated in this context. The contaminants in the labile and bioaccessible fraction along the MVC designed path and depth range might be released into the lagoon because of ship wakes, with a considerable amount in the mid-term. The potential bioavailability and bioaccessibility of contaminants were confirmed by the high ecotoxicity levels shown by elutriates obtained from sediment samples collected along the MVC trace. They generate concern as it represents an easily exchangeable fraction which can move from sediment to water. Proper measures should then be planned to limit the risk of contamination of the lagoon water during the years following dredging. Moreover, the modeling study provides a first evaluation of how the interruption of the caranto aquitard by the MVC digging favors the saltwater flow deepward in a medium to long time interval, in the range of a few decades. Electromagnetic surveys and marine electric topographies carried out in the part of the lagoon between Venice and Chioggia clearly pointed out that groundwater with a salt content similar to the marine waters is found beneath $5-15 \mathrm{~m}$ b.m.s.l. only where the caranto layer is cut, generally by natural erosion or channel excavation (Tosi et al., 2009; Zecchin et al., 2014). The modeling results suggest that the salt contamination remains localized around the incision, with an important role in controlling the depth of percolation played by the actual layering of the sedimentary deposits below the channel bottom.

\section{Conclusion}

This study presented the results of a systematic modeling investigation of the possible hydrological processes activated by digging a large and deep navigable channel through a shallow lagoon in the hydrogeological system below the lagoon bottom. Although the practice of dredging channels is quite common in coastal lagoons to facilitate the movement of goods and people from the outer sea to inner ports, a specific investigation of these effects had never been carried out before this study.
Here we focus on the specific case of the Venice Lagoon, where the new $10 \mathrm{~m}$ deep, $3 \mathrm{~km}$ long, and $150 \mathrm{~m}$ wide MVC canal is under planning. Results from the modeling approach show that a significant influence on the groundwater-surficial water exchange is expected to be produced by the excavation and the transit of cruise vessels along the channel. Each large ship in transit can produce a depression wake on the order of $1 \mathrm{~m}$, thus pumping out the groundwater from the shallow deposits around the excavation. Although for a given channel section the ship wake lasts a couple of minutes only, the large groundwater velocity induced in the surroundings of the excavation combined with the length of the MVC are responsible for an efflux on the order of $50-100 \mathrm{~m}^{3}$ per ship, i.e., $25000-50000 \mathrm{~m}^{3}$ year $^{-1}$. The contaminants in the labile and bioaccessible fraction along the MVC designed path and depth range might be released into the lagoon because of ship wakes, with a considerable amount in the mid-term. The potential bioavailability and bioaccessibility of contaminants was confirmed by the high ecotoxicity levels shown by elutriates obtained from sediment samples collected along the MVC trace. They generate concern as it represents an easily exchangeable fraction which can move from sediment to water. The propagation at depth of the seawater could also be enhanced over a multi-decadal time frame.

Proper measures should then be planned to limit the risk of contamination of the lagoon water during the years following dredging. Moreover, considering the importance and the fragility of the Lagoon of Venice, if the MCV is to become a real project, a variety of new and more detailed information will necessarily have to be collected to provide a more accurate quantification of the possible environmental impacts of the canal dredging on the subsurface system of the Venice Lagoon. For example, additional piezometers should be placed along the MMIC to verify in advance the ship-wake effects on the subsoil and along the planned MVC path to characterize the natural flow regime; groundwater age through isotope analyses of water samples should be determined to evaluate the groundwater origin and fate; and pumping and tracer tests should be planned to characterize the hydrogeological properties of the shallow aquifers below the lagoon bottom.

Data availability. Data are available upon request to Pietro Teatini (pietro.teatini@unipd.it).

Competing interests. The authors declare that they have no conflict of interest.

Acknowledgements. The research was funded by the Venice Port Authority, Italy, and partially supported by the Flagship Project RITMARE - The Italian Research for the Sea, CNR-MIUR, National Research Program 2011-2013, "Linea SOLVE". 
Edited by: Alberto Guadagnini

Reviewed by: two anonymous referees

\section{References}

Amos, C. L., Umgiesser, G., Tosi, L., and Townend, I. H.: The coastal morphodynamics of Venice lagoon, Italy: An introduction, Cont. Shelf Res., 30, 837-846, https://doi.org/10.1016/j.csr.2010.01.014, 2010.

Anderson, M., Woessner, W., and Hunt, R.: Applied Groundwater Modeling - Simulation of Flow and Advective Transport, 2nd Edition, Academic Press, London, UK, 630 pp., 2015.

Arizzi Novelli, A., Losso, C., Libralato, G., Tagliapietra, D., Pantani, C., and Volpi Ghirardini, A.: Is the $1: 4$ elutriation ratio reliable? Ecotoxicological comparison of four different sediment:water proportions, Ecotox. Environ. Safe., 65, 306-313, https://doi.org/10.1016/j.ecoenv.2005.08.010, 2006.

Balletti, C.: Digital elaborations for cartographic reconstruction: the territorial transformations of Venice harbours in historical maps, E-Perimetron, 1, 274-286, 2006.

Baradello, L. and Carcione, J. M.: Optimal seismic-data acquisition in very shallow waters: Surveys in the Venice lagoon, Geophysics, 73, Q59-Q63, https://doi.org/10.1190/1.2976117, 2008.

Bear, J.: Hydraulics of Groundwater, McGraw-Hill, New York, USA, 1979.

Bellafiore, D. and Umgiesser, G.: Hydrodynamic coastal processes in the North Adriatic investigates with a 3D finite element model, Ocean Dynam., 60, 255-273, https://doi.org/10.1007/s10236-009-0254-x, 2010.

Bredehoeft, J. D. and Pinder, G. F.: Mass transport in flowing groundwater, Water Resour. Res., 9, 194-210, https://doi.org/10.1029/WR009i001p00194, 1973.

Broglia, R., Zaghi, S., Muscari, R., and Salvadore, F.: Enabling hydrodynamics solver for efficient parallel simulations, in: Proc. Int. Conf. on High Performance Computing \& Simulation (HPCS), 21-25 July 2014, Bologna, Italy, IEEE, 803-810, https://doi.org/10.1109/HPCSim.2014.6903770, 2014.

Camporese, M., Paniconi, C., Putti, M., and Orlandini, S.: Surfacesubsurface flow modeling with path-based runoff routing, boundary condition-based coupling, and assimilation of multisource observation data, Water Resour. Res., 46, W02512, https://doi.org/10.1029/2008WR007536, 2010.

Carniello, L., Defina, A., and D’Alpaos, L.: Morphological evolution of the Venice lagoon: Evidence from the past and trend for the future, J. Geophys. Res.-Earth, 114, F04002, https://doi.org/10.1029/2008JF001157, 2009.

Castelletto, N., Gambolati, G., and Teatini, P.: A coupled MFE poromechanical model of a large-scale load experiment at the coastland of Venice, Comput. Geosci., 19, 17-29, https://doi.org/10.1007/s10596-014-9450-y, 2015.

Corami, F., Cairns, W. R., Rigo, C., Vecchiato, M., Piazza, R., and Cescon, P.: Remediation and bioremediation of dredged polluted sediments of the Venice Lagoon, Italy: An environmentalfriendly approach, in: Int. Congress "The Centenary" 100th Anniversary of the Italian Chemical Society, 31 August-4 September 2009, Padova, Italy, 2009.
D'Alpaos, L.: Fatti e Misfatti di Idraulica Lagunare - La Laguna di Venezia dalla Diversione dei Fiumi alle Nuove Opere alle Bocche di Porto, Istituto Veneto di SS.LL.AA., Italy, 329 pp., 2010.

Department of Environmental and Computer Science and Statistics (DAIS): Environmental Status of the Venice Lagoon and Elements of Urban Development Planning for the Port Services and Activities, Final Report, Ca' Foscari University, Venice, Italy, 2016.

Di Mascio, A., Broglia, R., and Muscari, R.: On the application of the single-phase level set method to naval hydrodynamic flows, Comput. Fluids, 36, 868-886, https://doi.org/10.1016/j.compfluid.2006.08.001, 2007.

Di Mascio, A., Broglia, R., and Muscari, R.: Prediction of hydrodynamic coefficients of ship hulls by high-order Godunov-type methods, J. Mar. Sci. Technol., 14, 19-29, https://doi.org/10.1007/s00773-008-0021-6, 2009.

Duck, R. W. and da Silva, J. F.: Coastal lagoons and their evolution: A hydromorphological perspective, Estuar. Coast. Shelf S., 110, 2-14, https://doi.org/10.1016/j.ecss.2012.03.007, 2012.

Erftemeijer, P. L. A. and Lewis III, R. R. R.: Environmental impacts of dredging on seagrasses: A review, Mar. Pollut. Bull., 52, 1553-1572, https://doi.org/10.1016/j.marpolbul.2006.09.006, 2006.

Fabbri, P., Zangheri, P., Bassan, V., Fagarazzi, E., Mazzuccato, A., Primon, S., and Zogno, C.: Sistemi idrogeologici della provincia di Venezia - acquiferi superficiali. Provincia di Venezia, Università degli Studi di Padova, Italy, Cierre Grafica Publ., 127 pp., 2013.

Ferrarin, C., Ghezzo, M., Umgiesser, G., Tagliapietra, D., Camatti, E., Zaggia, L., and Sarretta, A.: Assessing hydrological effects of human interventions on coastal systems: numerical applications to the Venice Lagoon, Hydrol. Earth Syst. Sci., 17, 1733-1748, https://doi.org/10.5194/hess-17-1733-2013, 2013.

Fortunato, A. B. and Oliveiram, A.: Case study: Promoting the stability of the Óbidos Lagoon inlet, J. Hydraul. Eng., 133, 816-824, https://doi.org/10.1061/(ASCE)07339429(2007)133:7(816), 2007.

Gallo, C., Paniconi, C., and Gambolati, G.: A comparison of solution approaches for the two-domain model of non equilibrium transport in porous media, Adv. Water Resour., 19, 241-253, https://doi.org/10.1016/0309-1708(96)00003-6, 1996.

Gerino, M., Frignani, M., Mugnai, C., Bellucci, L. G., Prevedelli, D., Valentini, A., Castelli, A., Delmotte, S., and Sauvage, S.: Bioturbation in the Venice Lagoon: Rates and relationship to organisms, Acta Oecol., 32, 14-25, https://doi.org/10.1016/j.actao.2007.02.003, 2007.

Gieskes, J. M., Han, S., Rathburn, A., Rothwell, G., Pérez, M. E., Porrachia, M., Barbanti, A., and Deheyn, D. D.: Anthropogenic contaminants in Venice Lagoon sediments and their pore fluids: Results from the SIOSED Project, Mar. Chem., 174, 73-84, https://doi.org/10.1016/j.marchem.2015.05.008, 2015.

Gingras, M. K., Pemberton, S. G., and Smith, M.: Bioturbation: Reworking sediments for better or worse, Oilfield Rev., 26, 46-58, 2015.

Gong, W., Shen, J., and Jia, J.: The impact of human activities on the flushing properties of a semi-enclosed lagoon: Xiaohai, Hainan, China, Mar. Environ. Res., 65, 62-76, https://doi.org/10.1016/j.marenvres.2007.08.001, 2008. 
Healy, T., Mathew, J., de Lange, W., and Black, K.: Adjustments toward equilibrium of a large flood-tidal delta after a major dredging program, Tauranga harbour, New Zealand, in: Coastal Engineering, edited by: Edge, B. L., ASCE Publ., Reston, VA, USA, 3284-3294, 1996.

Kennish, M. J. and Paerl, H. W. (Eds): Coastal Lagoons: Critical Habitats of Environmental Change, CRC Press, Boca Raton, FL, USA, 2010.

Lee, P. K., Kang, M. J., Yu, S., Ko, K. S., Ha, K., Shin, S. C., and Park, J. H.: Enrichment and geochemical mobility of heavy metals in bottom sediment of the Hoedong reservoir, Korea and their source apportionment, Chemosphere, 184, 74-85, https://doi.org/10.1016/j.chemosphere.2017.05.124, 2017.

Li, L., Barry, D. A., Stagnitti, F., and Parlange, J. Y.: Submarine groundwater discharge and associated chemical input to a coastal sea, Water Resour. Res., 35, 3253-3259, https://doi.org/10.1029/1999wr900189, 1999.

Libralato, G., Losso, C., Arizzi Novelli, A., Citron, M., Della Sala, S., Zanotto, E., Cepak, F., and Volpi Ghirardini, A.: Ecotoxicological evaluation of industrial port of Venice (Italy) sediment samples after a decontamination treatment, Environ. Pollut., 156, 644-650, https://doi.org/10.1016/j.envpol.2008.06.025, 2008.

López, R. A., Marcomini, S. C., and Kalesnik, F.: Artificial lakes management in the estuarine plain of the Río de la Plata, Buenos Aires, Argentina, Ocean Coast. Manage., 77, 66-72, https://doi.org/10.1016/j.ocecoaman.2012.03.002, 2013.

Losso, C., Arizzi Novelli, A., Picone, M., Ghetti, P. F., and Volpi Ghirardini, A.: Porewater as a matrix in toxicity bioassays with sea urchins and bivalves: Evaluation of applicability to the Venice lagoon (Italy), Environ. Int., 35, 118-126, https://doi.org/10.1016/j.envint.2008.09.010, 2009.

Losso, C., Arizzi Novelli, A., De Salvador, D., Ghetti, P. F., and Volpi Ghirardini, A.: Integration of biological responses from a suite of bioassays for the Venice Lagoon (Italy) through sediment toxicity index - Part A: Development and comparison of two methodological approaches, Environ. Pollut., 158, 3655-3662, https://doi.org/10.1016/j.envpol.2010.07.038, 2010.

Madricardo, F. and Donnici, S.: Mapping past and recent landscape modifications in the Lagoon of Venice through geophysical surveys and historical maps, Anthropocene, 6, 86-96, https://doi.org/10.1016/j.ancene.2014.11.001, 2014

Marani, M., D’Alpaos, A., Lanzoni, S., and Santalucia, M.: Understanding and predicting wave erosion of marsh edges, Geophys, Res. Lett., 38, L21401, https://doi.org/10.1029/2011GL048995, 2011.

Mazzia, A. and Putti, M.: Three-dimensional mixed finite elementfinite volume approach for the solution of density-dependent flow in porous media, J. Comput. Appl. Math., 185, 347-359, https://doi.org/10.1016/j.cam.2005.03.015, 2006.

Michael, H. A., Mulligan, A. E., and Harvey, C. F.: Seasonal oscillations in water exchange between aquifers and the coastal ocean, Nature, 436, 1145-1148, https://doi.org/10.1038/nature03935, 2005.

Molinaroli, E., Guerzoni, S., Sarretta, A., Masiol, M., and Pistolato, M.: Thirty-year changes (1970 to 2000) in bathymetry and sediment texture recorded in the Lagoon of Venice sub-basins, Italy, Mar. Geol., 258, 115-125, https://doi.org/10.1016/j.margeo.2008.12.001, 2009.
Nakada, S., Yasumoto, J., Taniguchi, M., and Ishitobi, T.: Submarine groundwater discharge and seawater circulation in a subterranean estuary beneath a tidal flat, Hydrol. Process., 25, 27552763, https://doi.org/10.1002/hyp.8016, 2011.

Newell, R. C., Seiderer, L. J., and Hitchock, D. R.: The impact of dredging works in coastal waters: a review of the sensitivity to disturbance and subsequent recovery of biological resources on the sea bed, Oceanogr. Mar. Biol., 36, 127-178, 1998.

Oczkowsly, A. J. and Nixon, S. W.: Lagoons of the Nile Delta, in: Coastal Lagoons - Critical Habitats of Environmental Change, edited by: Kennish, M. J. and Paerl, H. W., CRC Press, Boca Raton, FL, USA, 253-283, 2010.

Paniconi, C. and Putti, M.: A comparison of Picard and Newton iteration the numerical solution of multidimensional variably saturated flow problems, Water Resour. Res., 30, 3357-3374, https://doi.org/10.1029/94WR02046, 1994.

Paris, A., Teatini, P., Venturini, S., Gambolati, G., and Bernstein, A. G.: Hydrological effects of bounding the Venice (Italy) industrial harbour by a protection cut-off wall: A modeling study, J. Hydrol. Eng., 15, 882-891, https://doi.org/10.1061/(ASCE)HE.1943-5584.0000258, 2011.

Qu, W., Li, H., Wan, L., Wang, X., and Jiang, X.: Numerical simulations of steady-state salinity distribution and submarine groundwater discharges in homogeneous anisotropic coastal aquifers, Adv. Water. Res., 74, 318-328, https://doi.org/10.1016/j.advwatres.2014.10.009, 2014.

Qiao, Y., Yang, Y., Gu, J., and Zhao, J.: Distribution and geochemical speciation of heavy metals in sediments from coastal area suffered rapid urbanization, a case study of Shantou Bay, China, Mar. Pollut. Bull., 68, 140-146, https://doi.org/10.1016/j.marpolbul.2012.12.003, 2013.

Rapaglia, J.: Submarine groundwater discharge into Venice Lagoon, Italy, Estuaries, 28, 705-713, https://doi.org/10.1007/BF02732909, 2005.

Rapaglia, J., Zaggia, L., Parnell, K., Lorenzetti, G., and Vafeidis, A. T.: Ship-wake induced sediment remobilization: Effects and proposed management strategies for the Venice Lagoon, Ocean Coast. Manage., 110, 1-11, https://doi.org/10.1016/j.ocecoaman.2015.03.002, 2015.

Rinaldo, A.: On the Natural Equilibrium of the Venice Lagoon (Will Venice Survive?), in: Sustainable Venice: Suggestions for the Future, edited by: Musu, I., Kluwer, Dordrecht, the Netherlands, 61-94, 2001

Rocha, C., Veiga-Pires, C., Scholten, J., Knoeller, K., Gröcke, D. R., Carvalho, L., Anibal, J., and Wilson, J.: Assessing land-ocean connectivity via submarine groundwater discharge (SGD) in the Ria Formosa Lagoon (Portugal): combining radon measurements and stable isotope hydrology, Hydrol. Earth Syst. Sci., 20, 3077 3098, https://doi.org/10.5194/hess-20-3077-2016, 2016.

Santos, I. R., Niencheski, F., Burnett, W., Peterson, R., Chanton, J., Andrade, C. F. F., Milani, I. B., Schmidt, A., and Knoeller, K.: Tracing anthropogenically driven groundwater discharge into a coastal lagoon from southern Brazil, J. Hydrol., 353, 275-293, https://doi.org/10.1016/j.jhydrol.2008.02.010, 2008.

Schintu, M., Marrucci, A., Marras, B., Galgani, F., Buosi, C., Ibba, A., and Cherchi, A.: Heavy metal accumulation in surface sediments at the port of Cagliari (Sardinia, western Mediterranean): Environmental assessment using sequential extrac- 
tions and benthic foraminifera, Mar. Pollut. Bull., 111, 45-56, https://doi.org/10.1016/j.marpolbul.2016.07.029, 2016.

Tait, D. R., Santos, I. R., Erler, D. V., Befus, K. M., Cardenas, M. B., and Eyre, B. D.: Estimating submarine groundwater discharge in a South Pacific coral reef lagoon using different radioisotope and geophysical approaches, Mar. Chem., 156, 49-60, https://doi.org/10.1016/j.marchem.2013.03.004, 2013.

Tambroni, N. and Seminara, G.: Are inlets responsible for the morphological degradation of Venice Lagoon?, J. Geophys. Res.-Earth, 111, F03013, https://doi.org/10.1029/2005JF000334, 2006.

Teatini, P., Tosi, L., Viezzoli, A., Baradello, L., Zecchin, M., and Silvestri, S.: Understanding the hydrogeology of the Venice Lagoon subsurface with airborne electromagnetics, J. Hydrol., 411, 342-354, https://doi.org/10.1016/j.jhydrol.2011.10.017, 2011.

Tessier, A., Campbell, P. G. C., and Bisson, M.: Sequential extraction procedure for the speciation of particulate trace metals, Anal. Chem., 51, 844-851, 1979.

Thomsen, M. S., Adam, P., and Silliman, B. R.: Anthropogenic threats of Australasian coastal salt marshes, in: Human Impacts on Salt Marshes: A Global Perspective, edited by: Silliman, B. R., Grosholz, E. D., and Bertness, M. D., University of California Press, Berkley, CA, USA, 361-390, 2009.

Tosi, L., Rizzetto, F., Bonardi, M., Donnici, S., Serandrei Barbero, R., and Toffoletto, F.: Note illustrative della Carta Geologica d'Italia alla scala 1:50000, Foglio 128 Venezia. APAT, Dip. Difesa del Suolo, Servizio Geologico d'Italia, SystemCart, Roma, Italy, 164 pp., 2007.

Tosi, L., Rizzetto, F., Zecchin, M., Brancolini, G., and Baradello, L.: Morphostratigraphic framework of the Venice Lagoon (Italy) by very shallow water VHRS surveys: evidence of radical changes triggered by human-induced river diversion, Geophys. Res. Lett., 36, L09406, https://doi.org/10.1029/2008GL037136, 2009.

Tosi, L., Baradello, L., Teatini, P., Zecchin, M., Bonardi, M., Shi, P., Tang, C., Li, F., Brancolini, G., Chen, Q., Chiozzotto, B., Frankenfield, J., Giada, M., Liu, D., Nieto, D., Rizzetto, F., Sheng, Y., Xiao, Y., and Zhou, D.: Combined continuous electrical tomography and very high resolution seismic surveys to assess continental and marine groundwater mixing, B. Geofis. Teor. Appl., 52, 585-594, https://doi.org/10.4430/bgta0024, 2011.

Tsang, C.-F.: Is current hydrogeologic research addressing long-term predictions?, Ground Water, 43, 296-300, https://doi.org/10.1111/j.1745-6584.2005.0023.x, 2005.

Umgiesser, G., Melaku-Canu, D., Cucco, A., and Solidoro, C.: A finite element model for the Venice Lagoon. Development, set up, calibration and validation, J. Marine Syst., 51, 123-145, https://doi.org/10.1016/j.jmarsys.2004.05.009, 2004.
Ure, A. M., Quevauviller, P., Muntau, H., and Griepink, B.: Speciation of heavy metals in soils and sediments. An account of the improvement and harmonization of extraction techniques undertaken under the auspices of the BCR of the Commission of the European Communities, Int. J. Environ. An. Ch., 51, 135-151, 1993.

Viezzoli, A., Tosi, L., Teatini, P., and Silvestri, S.: Surface water-groundwater exchange in transitional coastal environments by airborne electromagnetics: The Venice Lagoon example, Geophys. Res. Lett., 37, L01402, https://doi.org/10.1029/2009GL041572, 2010.

Volpi Ghirardini, A., Arizzi Novelli, A., and Tagliapietra, D.: Sediment toxicity assessment in the Lagoon of Venice (Italy) using Paracentrotuslividus (Echinodermata: Echinoidea) fertilization and embryo bioassays, Environ. Int., 31, 1065-1077, https://doi.org/10.1016/j.envint.2005.05.017, 2005.

Wang, X., Li, H., Jiao, J. J., Barry, D. A., Li, L., Luo, X., Wang, C., Wan, L., Wang, X., Jiang, X., Ma, Q., and Qu, W.: Submarine fresh groundwater discharge into Laizhou Bay comparable to the Yellow River flux, Sci. Rep., 5, 8814, https://doi.org/10.1038/srep08814, 2015.

Weill, S., Mazzia, A., Putti, M., and Paniconi, C.: Coupling water flow and solute transport into a physically-based surfacesubsurface hydrological model, Adv. Water. Resour., 34, 128136, https://doi.org/10.1016/j.advwatres.2010.10.001, 2011.

Whipkey, R. Z. and Kirkby, M. J.: Flow within soil, in: Hillslope Hydrology, edited by: Kirkby, M. J., John Wiley \& Sons, New York, USA, 1121-1144, 1978.

Zecchin, M., Caffau, M., and Tosi, L.: Relationship between peat bed formation and climate changes during the last glacial in the Venice area, Sediment. Geol., 238, 172-180, https://doi.org/10.1016/j.sedgeo.2011.04.011, 2011.

Zecchin, M., Tosi, L., Caffau, M., Baradello, L., and Donnici, S.: Sequence stratigraphic significance of tidal channel systems in a shallow lagoon (Venice, Italy), The Holocene, 24, 646-658, https://doi.org/10.1177/0959683614526903, 2014.

Zhang, C., Shan, B., Tang, W., Dong, L., Zhang, W., and Pei, Y.: Heavy metal concentrations and speciation in riverine sediments and the risks posed in three urban belts in the Haihe Basin, Ecotox. Environ. Safe., 139, 263-271, https://doi.org/10.1016/j.ecoenv.2017.01.047, 2017.

Zonta, R., Botter, M., Cassin, D., Pini, R., Scattolin, M., and Zaggia L.: Sediment chemical contamination of a shallow water area close to the industrial zone of Porto Marghera (Venice Lagoon, Italy), Mar. Pollut. Bull., 55, 529-542, https://doi.org/10.1016/j.marpolbul.2007.09.024, 2007. 